\title{
Inhibition of Measles Viral Fusion is Enhanced by Targeting Multiple Domains of the Fusion Protein
}

\author{
Francesca T. Bovier ${ }^{1,2,3}$, Ksenia Rybkina $^{1,2}$, Sudipta Biswas ${ }^{1,4}$, Olivia Harder $^{5}$, Tara C. Marcink ${ }^{1,2}$, Stefan \\ Niewiesk $^{5}$, Anne Moscona ${ }^{1,2,6,7}$, Christopher A. Alabi ${ }^{4 \#,}$, Matteo Porotto ${ }^{1,2,3 \#}$ \\ ${ }^{1}$ Center for Host-Pathogen Interaction, Columbia University Vagelos College of Physicians and Surgeons, New \\ York, 10032, New York, USA \\ ${ }^{2}$ Department of Pediatrics, Columbia University Vagelos College of Physicians and Surgeons, New York, 10032, \\ New York, USA \\ ${ }^{3}$ Department of Experimental Medicine, University of Campania 'Luigi Vanvitelli', 81100, Caserta, Italy \\ ${ }^{4}$ Robert Frederick Smith School of Chemical and Biomolecular Engineering, Cornell University, Ithaca, 14853, New \\ York, USA \\ ${ }^{5}$ Department of Veterinary Biosciences, College of Veterinary Medicine, The Ohio State University, Columbus, \\ 43210, Ohio, USA \\ ${ }^{6}$ Department of Microbiology \& Immunology, Columbia University Vagelos College of Physicians and Surgeons, \\ New York, 10032, New York, USA \\ ${ }^{7}$ Department of Physiology \& Cellular Biophysics, Columbia University Vagelos College of Physicians and \\ Surgeons, New York, 10032, New York, USA \\ ${ }^{\#}$ Co-corresponding authors
}


Table S1: List of peptides and their modifications.

${ }^{\text {a} P e p t i d e ~ s e q u e n c e s: ~ A m i n o ~ a c i d ~ r e s i d u e s ~ a r e ~ r e p r e s e n t e d ~ i n ~ s i n g l e ~ l e t t e r ~ c o d e ; ~ A c ~}=$ Acetylated Nterminus; GSGSG = linker containing five amino acids; $\mathrm{D}-\mathrm{FFG}=\mathrm{D}$-amino acid has been used for the first phenyl alanine residue; $\mathrm{Z}$-D-FFG $=\mathrm{Z}$ is carbobenzoxy attached to the $\mathrm{N}$-terminus of the D-FFG sequence.

${ }^{\text {b}}$ Peptide types: FIP = Fusion Inhibitory Peptide; HRC = measles HRC derived peptide sequence starting from residue 450 and ending at residue 485 in measles $\mathrm{F}$ protein;

${ }^{\mathrm{c}} \mathrm{PEG}=$ polyethylene glycol; $\mathrm{Chol}=$ Cholesterol $) ;{ }^{\mathrm{d}}($ Peptide $=\mathrm{HRC} / \mathrm{FIP}-\mathrm{HRC} / \mathrm{FIP})$

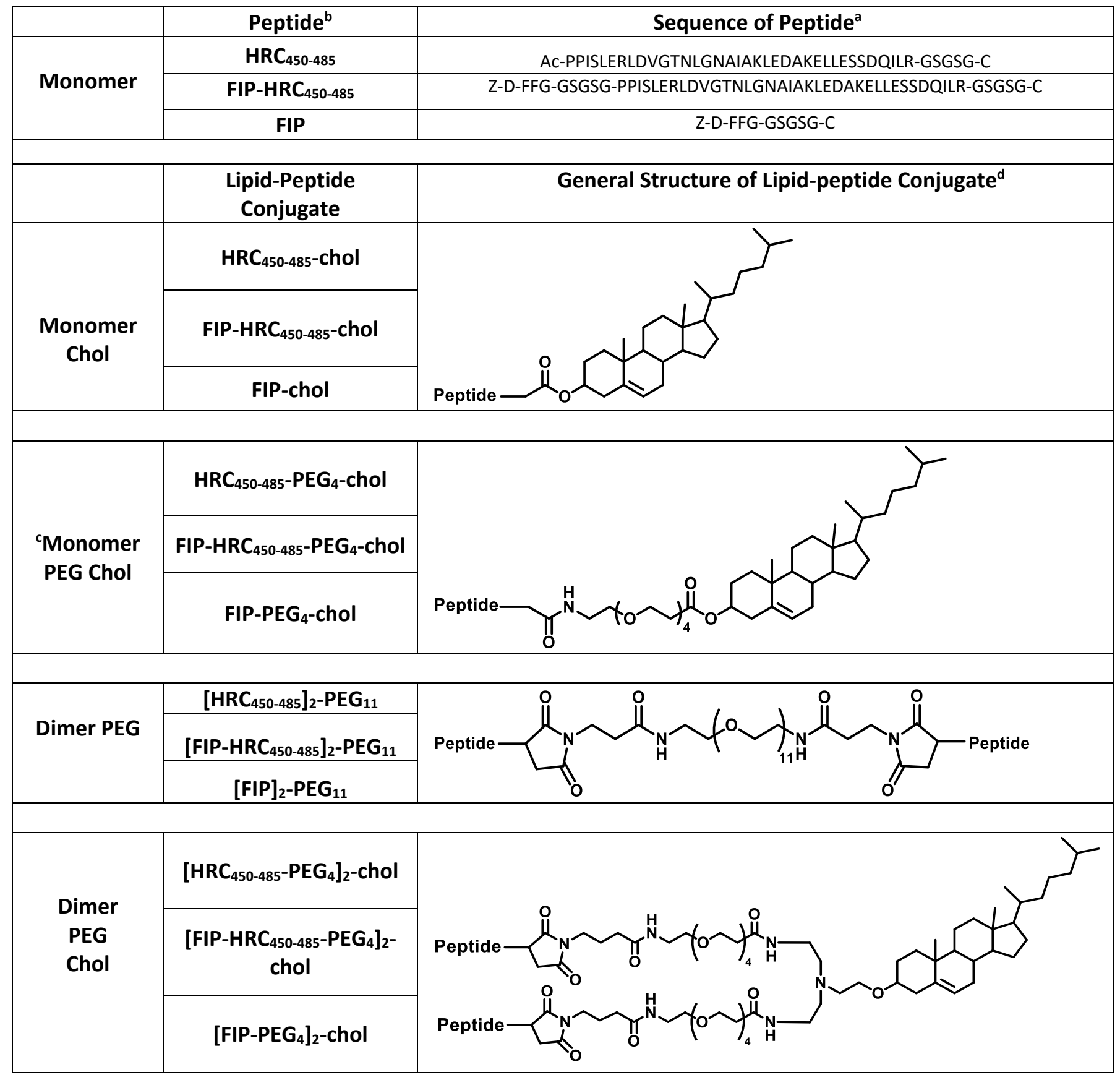




\section{Synthesis of peptide-cholesterol:}

General method to synthesize peptide-cholesterol conjugates (1):

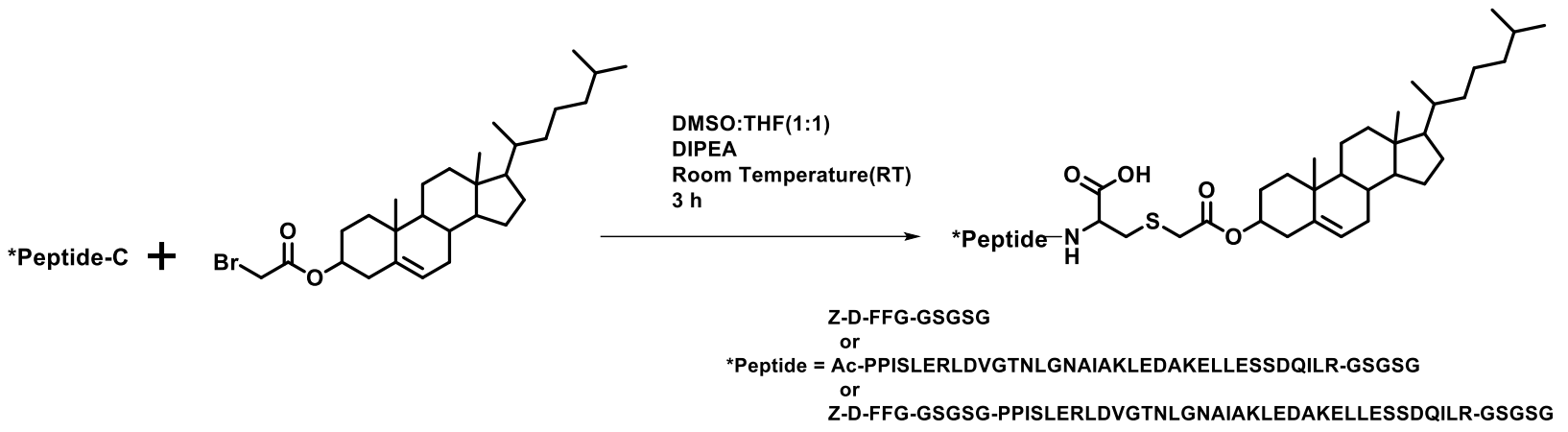

Scheme S1. Reaction scheme showing synthesis of peptide-cholesterol; *Peptide : C is cysteine in Peptide$\mathrm{C}$; Amino acid residues are represented in single letter code; $\mathrm{Ac}=$ Acetylated N-terminus; $\mathrm{GSGSG}=$ linker containing five amino acids; D-FFG $=\mathrm{D}$-amino acid was used for the first phenyl alanine residue; Z-D$\mathrm{FFG}=\mathrm{Z}$ is a carbobenzoxy residue attached to the $\mathrm{N}$-terminus of the D-FFG sequence.

$50 \mathrm{mg}$ of peptide, dissolved in $500 \mu \mathrm{L}$ of dimethylsulfoxide (DMSO), was added to bromoacetyl cholesterol (1.1 equivalent) dissolved in $500 \mu \mathrm{L}$ of tetrahydrofuran (THF), followed by the addition of $N, N$ diisopropylethylamine (DIPEA) (10 equivalent) to the solution. The solution was left stirring at room temperature for 3 hours, then purified by Phenomenex Jupiter C4 LC column $300 \AA$ ( $150 \times 21.2 \mathrm{~mm}$, particle size $5 \mu \mathrm{m}$ ) using as eluents: (A) $0.1 \%$ trifluoroacetic acid in water and (B) $0.1 \%$ trifluoroacetic acid in acetonitrile. The following linear gradient at a flow rate of $20 \mathrm{~mL} / \mathrm{min}$ was used: $50-70 \%$ (B) over 20 min, followed by $70-100 \%$ (B) in $3 \mathrm{~min}$, and then a wash step at $100 \%$ (B) for $3 \mathrm{~min}$. The desired peak was collected and lyophilized to give the product as white powder which was confirmed by MALDI. 


\section{Synthesis of FIP-HRC $450-485-\mathrm{chol}$ :}

FIP-HRC $450-485$-chol was synthesized and purified following procedure (1). The HPLC trace of the reaction mixture (retention time of the product - $13.1 \mathrm{~min}$ ) and MALDI data of the product are shown below.
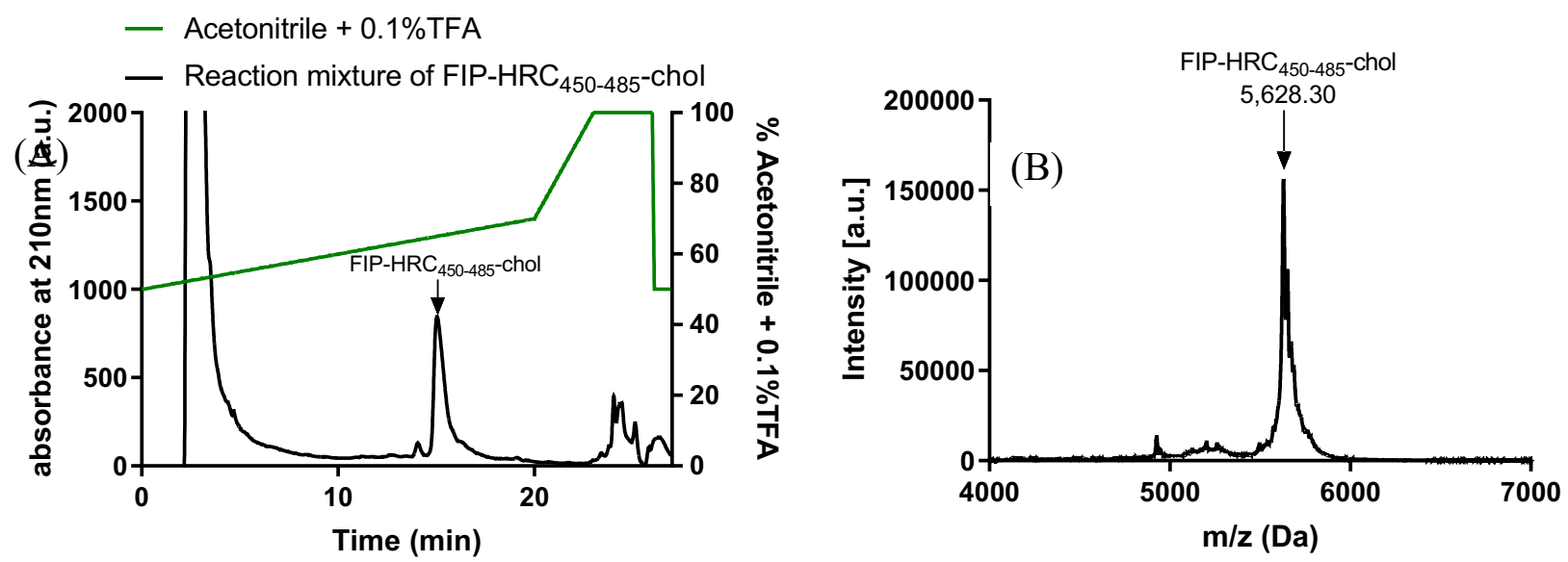

Fig. S1: HPLC and mass analysis of FIP-HRC $450-485$-chol (A) RP HPLC chromatogram of the reaction mixture; (B) MALDI mass spectrum of FIP-HRC $450-485$-chol [Calculated mass: 5,626.35; Observed mass: $5,628.30]$ 


\section{Synthesis of $\mathrm{HRC}_{450-485}$-chol:}

$\mathrm{HRC}_{450-485}$-chol was synthesized and purified following procedure (1). The HPLC trace of the reaction mixture (retention time of the product $-11.5 \mathrm{~min}$ ) and MALDI data of the product are shown below.

(A) - Acetonitrile + 0.1\% TFA

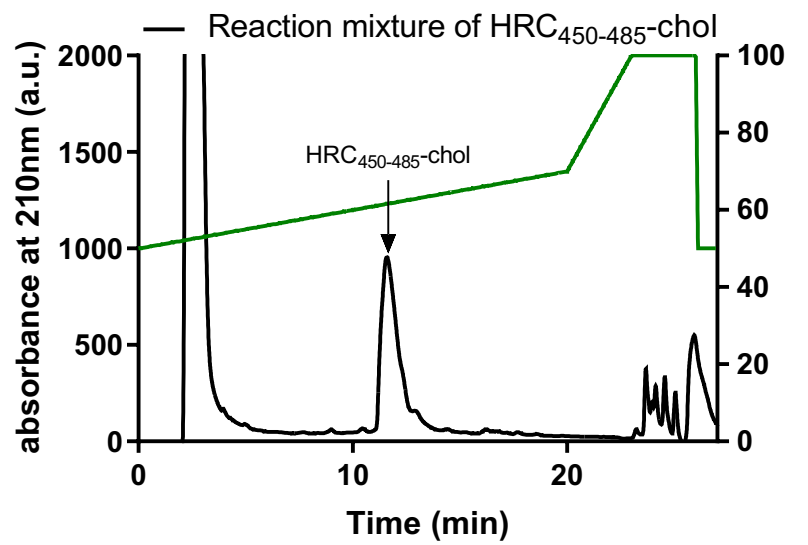

(B)

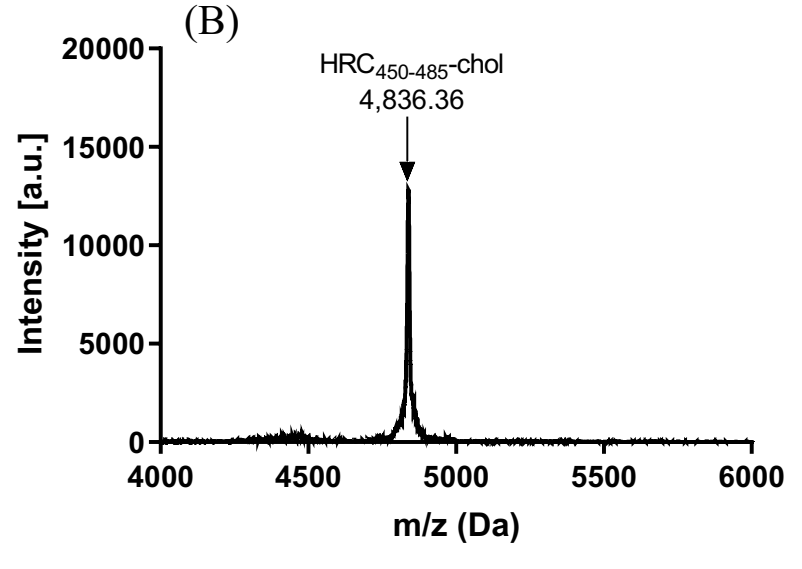

Fig. S2: HPLC and mass analysis of $\mathrm{HRC}_{450-485}$-chol (A) RP HPLC chromatogram of the reaction mixture; (B) MALDI mass spectrum of $\mathrm{HRC}_{450-485}$-chol [Calculated mass: 4,837.45; Observed mass: 4,836.36] 


\section{Synthesis of FIP-chol:}

FIP-chol was synthesized and purified following procedure (1). The HPLC trace of the reaction mixture (retention time of the product $-24.2 \mathrm{~min}$ ) and MALDI data of the product are shown below.

(A)

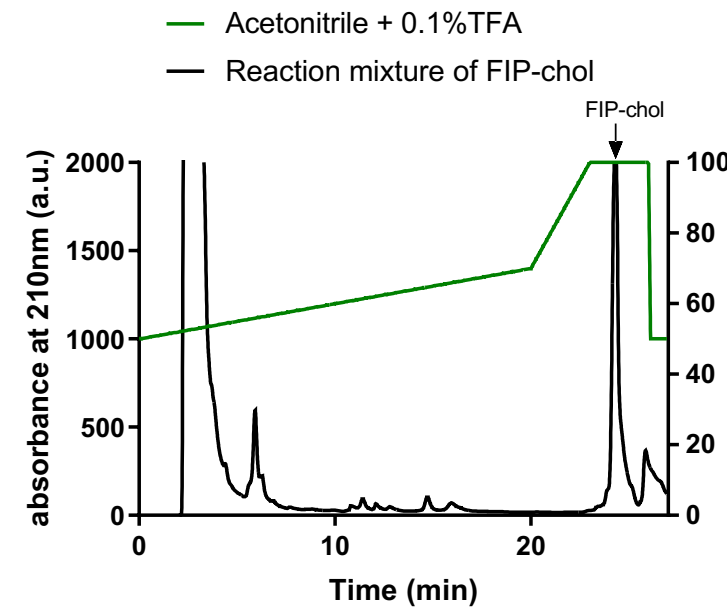

(B)

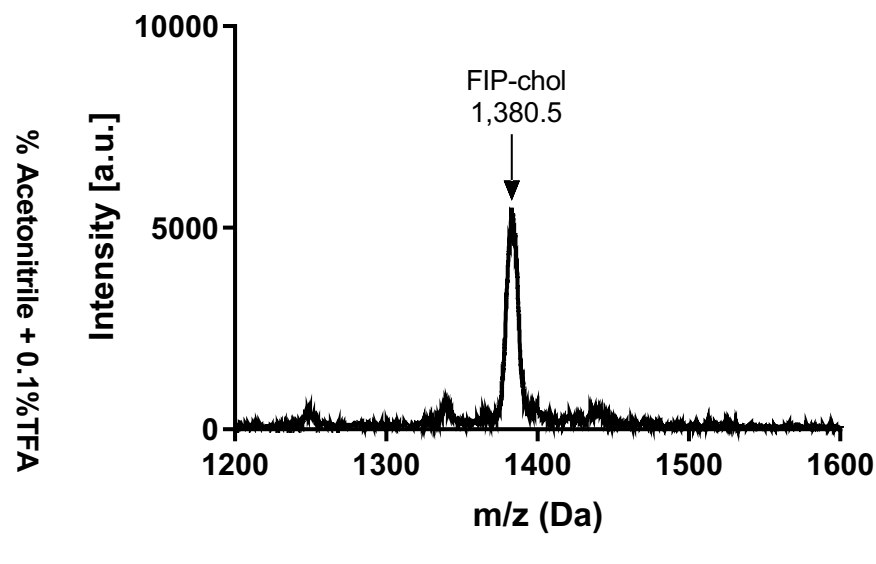

Fig. S3: HPLC and mass analysis of FIP-chol (A) RP HPLC chromatogram of the reaction mixture; (B) MALDI mass spectrum of FIP-chol [Calculated mass: 1,378.05; Observed mass: 1,380.5] 


\section{Synthesis of peptide-PEG $\mathbf{4}_{\mathbf{4}}$-cholesterol:}

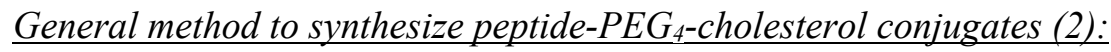

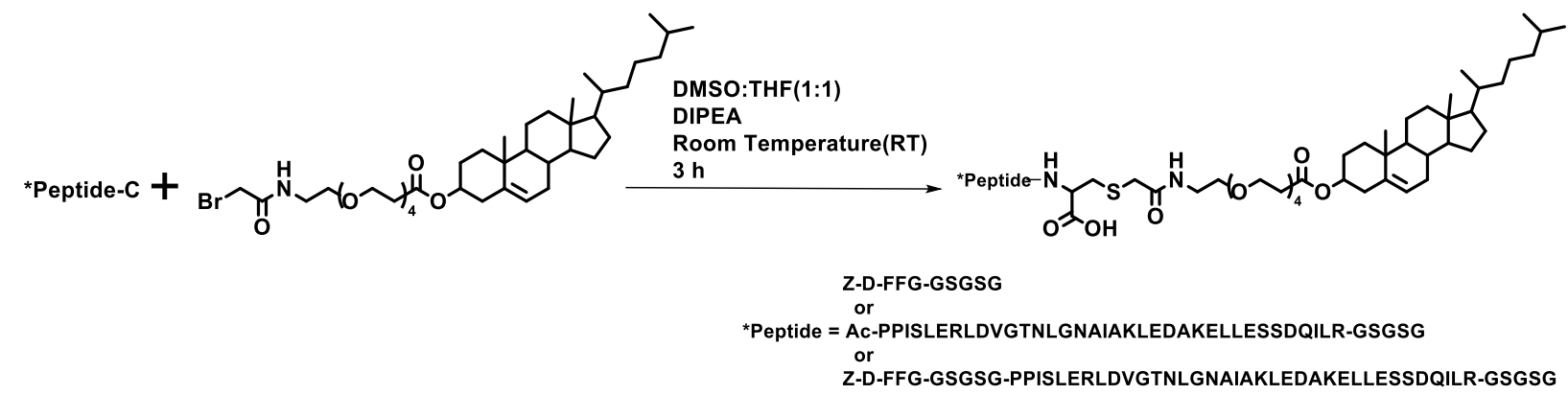

Scheme S2. Reaction scheme showing synthesis of peptide-PEG4-cholesterol; *Peptide : C is cysteine in Peptide-C; Amino acid residues are represented in single letter code; Ac = Acetylated N-terminus; GSGSG $=$ linker containing five amino acids; $\mathrm{D}-\mathrm{FFG}=\mathrm{D}$-amino acid was used for the first phenyl alanine residue; $\mathrm{Z}$-D-FFG $=\mathrm{Z}$ is a carbobenzoxy residue attached to the $\mathrm{N}$-terminus of the D-FFG sequence; PEG = polyethylene glycol.

$50 \mathrm{mg}$ of peptide, dissolved in $500 \mu \mathrm{L}$ of dimethylsulfoxide (DMSO), was added to bromoacetyl cholesterol (1.1 equivalent) dissolved in $500 \mu \mathrm{L}$ of tetrahydrofuran (THF), followed by the addition of $N, N$ diisopropylethylamine (DIPEA) (10 equivalent) to the solution. The solution was left stirring at room temperature for 3 hours, then purified by Phenomenex Jupiter C4 LC column $300 \AA(150 \times 21.2 \mathrm{~mm}$, particle size $5 \mu \mathrm{m}$ ) using as eluents: (A) $0.1 \%$ trifluoroacetic acid in water and (B) $0.1 \%$ trifluoroacetic acid in acetonitrile. The following linear gradient at a flow rate of $20 \mathrm{~mL} / \mathrm{min}$ was used: $50-70 \%$ (B) over 20 min, followed by $70-100 \%$ (B) in $3 \mathrm{~min}$, and then a wash step at 100\% (B) for $3 \mathrm{~min}$. The desired peak was collected and lyophilized to give the product as white powder which was confirmed by MALDI. 


\section{Synthesis of FIP-HRC $450-485-\mathrm{PEG}_{4}$-chol:}

FIP-HRC $450-485-\mathrm{PEG}_{4}$-chol was synthesized and purified following procedure (2). The HPLC trace of the reaction mixture (retention time of the product - $13.0 \mathrm{~min}$ ) and MALDI data of the product are shown below.

(A)

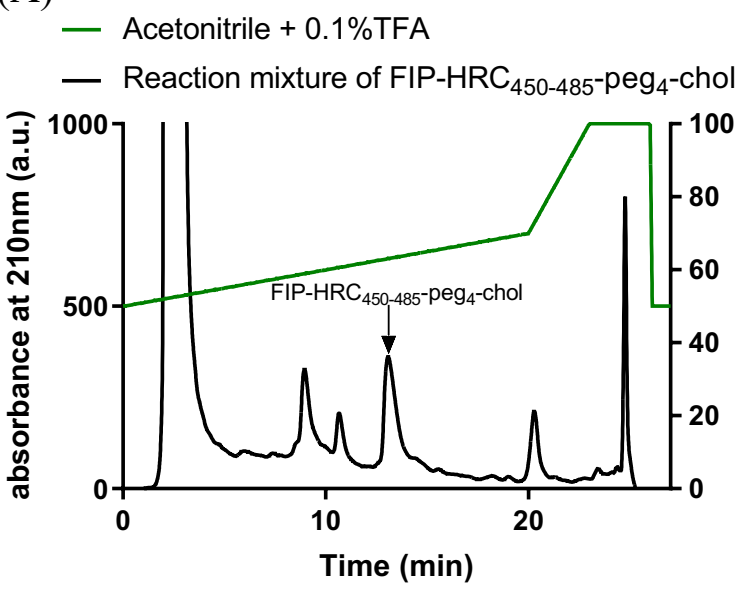

(B)

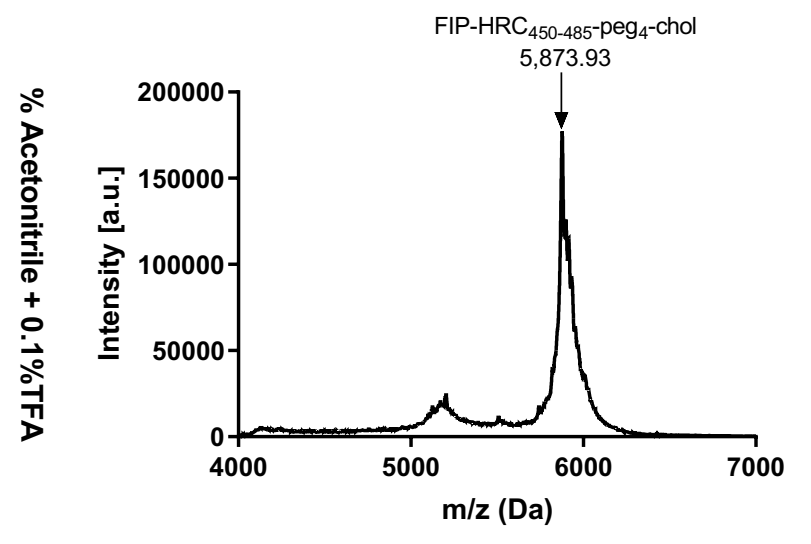

Fig. S4: HPLC and mass analysis of FIP-HRC $450-485-\mathrm{PEG}_{4}$-chol (A) RP HPLC chromatogram of the reaction mixture; (B) MALDI mass spectrum of FIP-HRC $450-485-$ PEG$_{4}$-chol [Calculated mass: 5,872.75; Observed mass: 5,873.93] 


\section{Synthesis of $\mathrm{HRC}_{450-485}-\mathrm{PEG}_{4}$-chol:}

$\mathrm{HRC}_{450-485}-\mathrm{PEG}_{4}$-chol was synthesized and purified following procedure (2). The HPLC trace of the reaction mixture (retention time of the product - $15.9 \mathrm{~min}$ ) and MALDI data of the product are shown below.

(A)

- Acetonitrile + 0.1\%TFA

- Reaction mixture of $\mathrm{HRC}_{450-485}-\mathrm{peg}_{4}$-chol

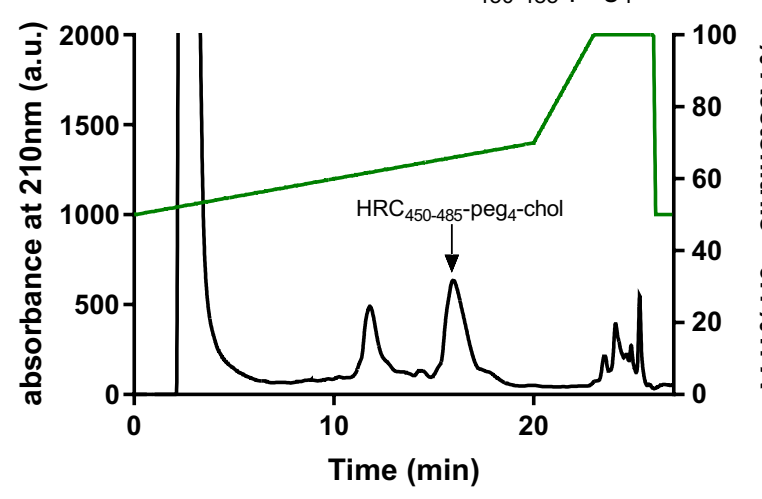

(B)

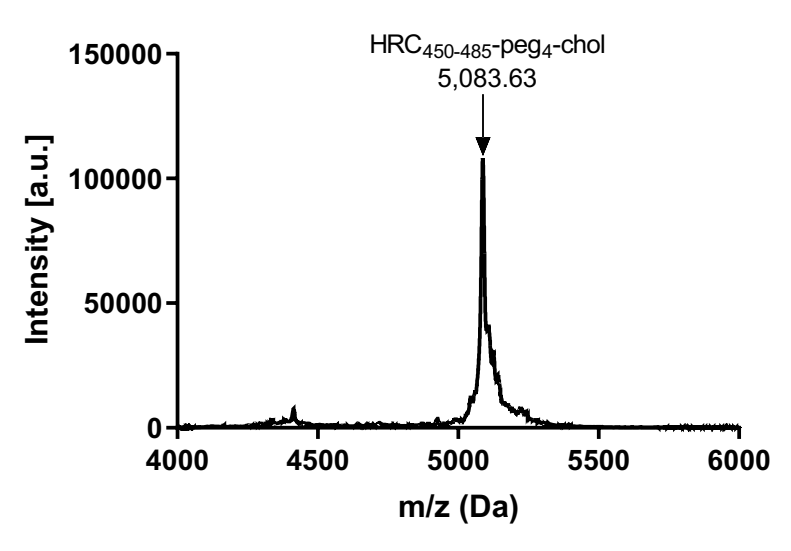

Fig. S5: HPLC and mass analysis of $\mathrm{HRC}_{450-485}-\mathrm{PEG}_{4}$-chol (A) RP HPLC chromatogram of the reaction mixture; (B) MALDI mass spectrum of $\mathrm{HRC}_{450-485}-\mathrm{PEG}_{4}$-chol [Calculated mass: 5,083.85; Observed mass: $5,083.63]$ 


\section{Synthesis of FIP-PEG 4 -chol:}

FIP-PEG 4 -chol was synthesized and purified following procedure (2). The HPLC trace of the reaction mixture (retention time of the product $-23.6 \mathrm{~min}$ ) and MALDI data of the product are shown below.

(A)

- Acetonitrile + 0.1\%TFA

- Reaction mixture of FIP- peg $_{4}$-chol

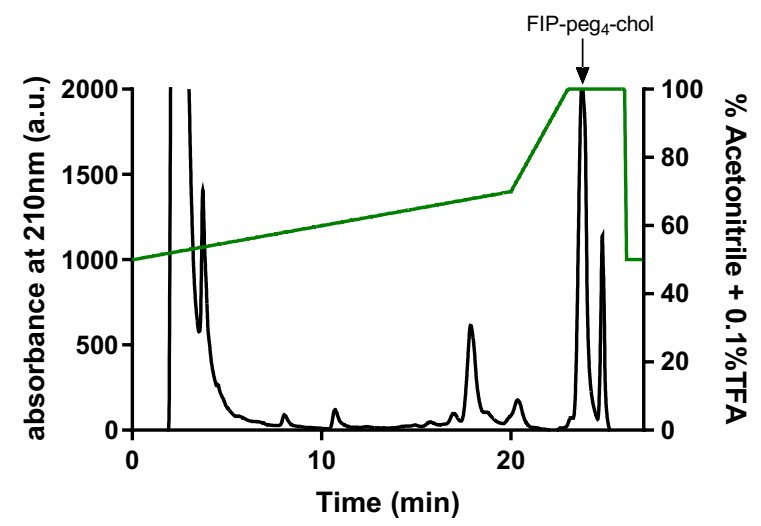

(B)

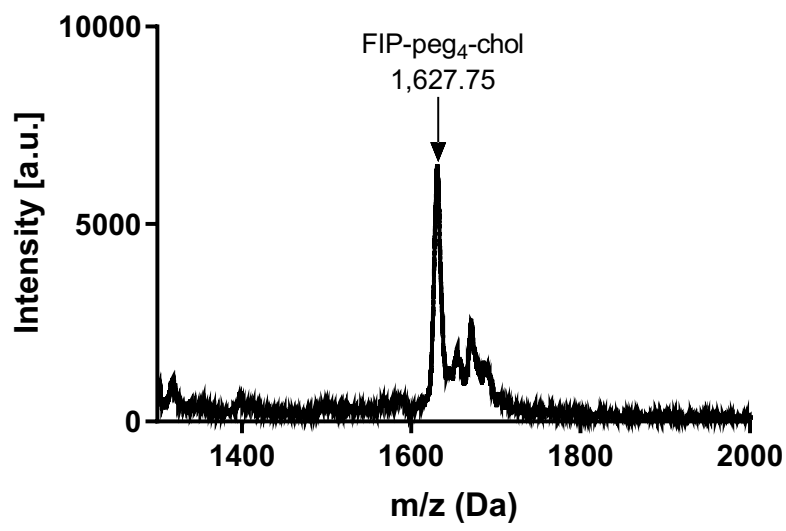

Fig. S6: HPLC and mass analysis of FIP-PEG 4 -chol (A) RP HPLC chromatogram of the reaction mixture; (B) MALDI mass spectrum of FIP- PEG 4 -chol [Calculated mass: 1,378.05; Observed mass: 1,380.5] 


\section{Synthesis of [peptide-PEG 4$]_{2}$-cholesterol:}

\section{General method to synthesize [peptide-PEG4]2-cholesterol conjugates (3):}

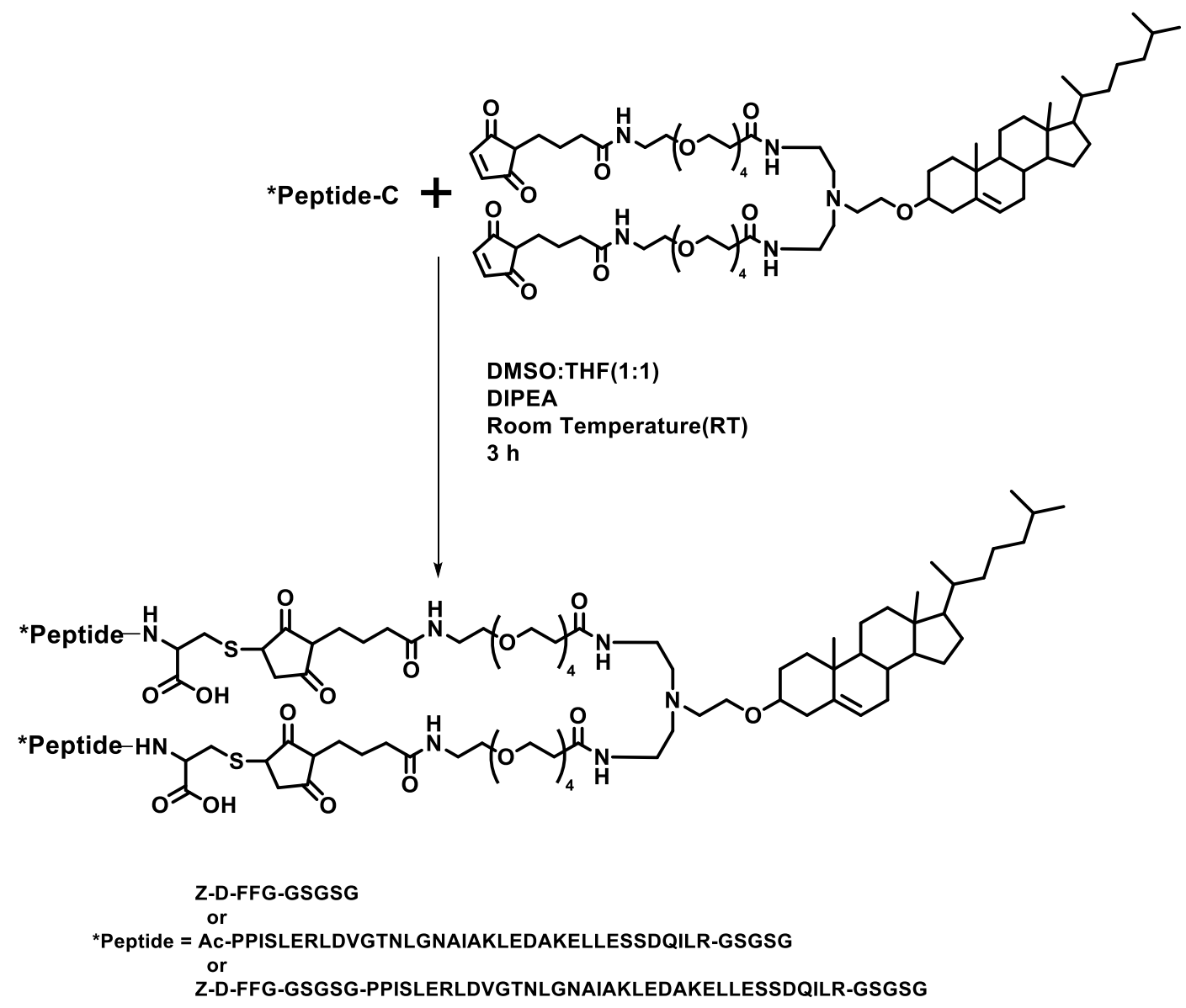

Scheme S3. Reaction scheme showing synthesis of [peptide-PEG $]_{2}$-cholesterol; *Peptide : C is cysteine in Peptide-C; Amino acid residues are represented in single letter code; Ac = Acetylated N-terminus; GSGSG $=$ linker containing five amino acids; $\mathrm{D}-\mathrm{FFG}=\mathrm{D}$-amino acid was used for the first phenyl alanine residue; $\mathrm{Z}-\mathrm{D}-\mathrm{FFG}=\mathrm{Z}$ is a carbobenzoxy residue attached to the $\mathrm{N}$-terminus of the D-FFG sequence; PEG = polyethylene glycol.

$50 \mathrm{mg}$ of peptide, dissolved in $500 \mu \mathrm{L}$ of dimethylsulfoxide (DMSO), was added to bromoacetyl cholesterol ( 0.5 equivalent) dissolved in $500 \mu \mathrm{L}$ of tetrahydrofuran (THF), followed by the addition of $N, N$ diisopropylethylamine (DIPEA) (10 equivalent) to the solution. The solution was left stirring at room temperature for 3 hours, then purified by Phenomenex Jupiter C4 LC column $300 \AA$ ( $150 \times 21.2 \mathrm{~mm}$, particle size $5 \mu \mathrm{m}$ ) using as eluents: (A) $0.1 \%$ trifluoroacetic acid in water and (B) $0.1 \%$ trifluoroacetic acid in acetonitrile. The following linear gradient at a flow rate of $20 \mathrm{~mL} / \mathrm{min}$ was used: $30-80 \%$ (B) over 20 min, followed by $80-100 \%$ (B) in $3 \mathrm{~min}$, and then a wash step at 100\% (B) for $3 \mathrm{~min}$. The desired peak was collected and lyophilized to give the product as white powder which was confirmed by MALDI. 


\section{Synthesis of [FIP-HRC $\left.{ }_{450-485}-\mathrm{PEG}_{4}\right]_{2}$-chol:}

[FIP-HRC $\left.450-485-\mathrm{PEG}_{4}\right]_{2}$-chol was synthesized and purified following procedure (3). The HPLC trace of the reaction mixture (retention time of the product - $12.6 \mathrm{~min}$ ) and MALDI data of the product are shown below.
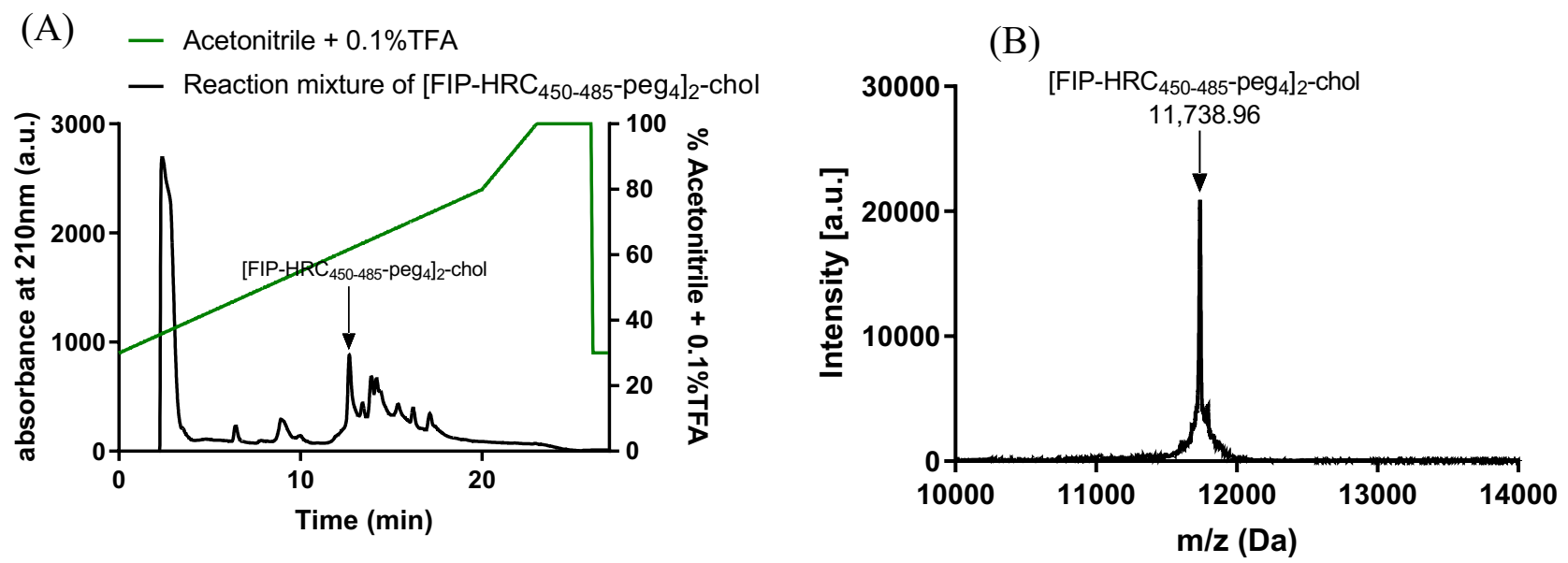

Fig. S7: HPLC and mass analysis of [FIP-HRC $\left.450-485-\mathrm{PEG}_{4}\right]_{2}$-chol (A) RP HPLC chromatogram of the reaction mixture; (B) MALDI mass spectrum of [FIP-HRC $\left.450-485-\mathrm{PEG}_{4}\right]_{2}$-chol [Calculated mass: 11,740.20; Observed mass: 11,738.96] 


\section{Synthesis of $\left[\mathrm{HRC}_{450-485}-\mathrm{PEG}_{4}\right]_{2}$-chol:}

$\left[\mathrm{HRC}_{450-485}-\mathrm{PEG}_{4}\right]_{2}$-chol was synthesized and purified following procedure (3). The HPLC trace of the reaction mixture (retention time of the product - $11.0 \mathrm{~min}$ ) and MALDI data of the product are shown below.

(A)

- Acetonitrile $+0.1 \%$ TFA

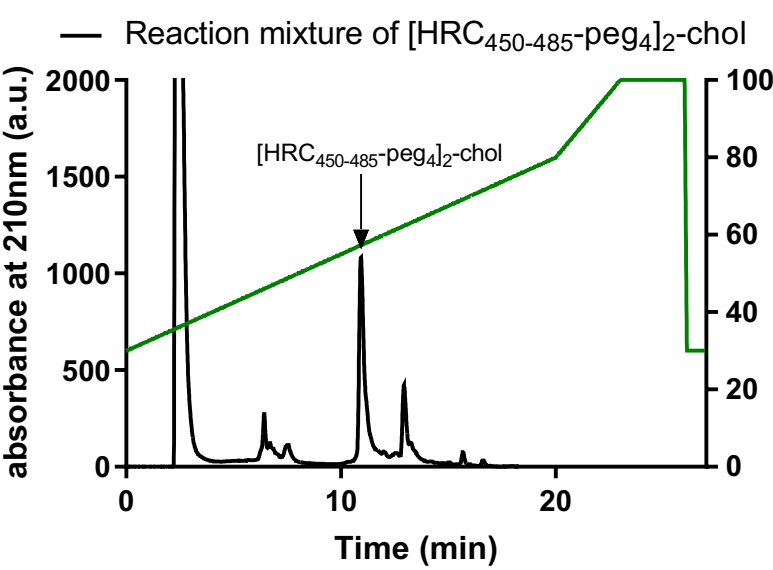

(B)

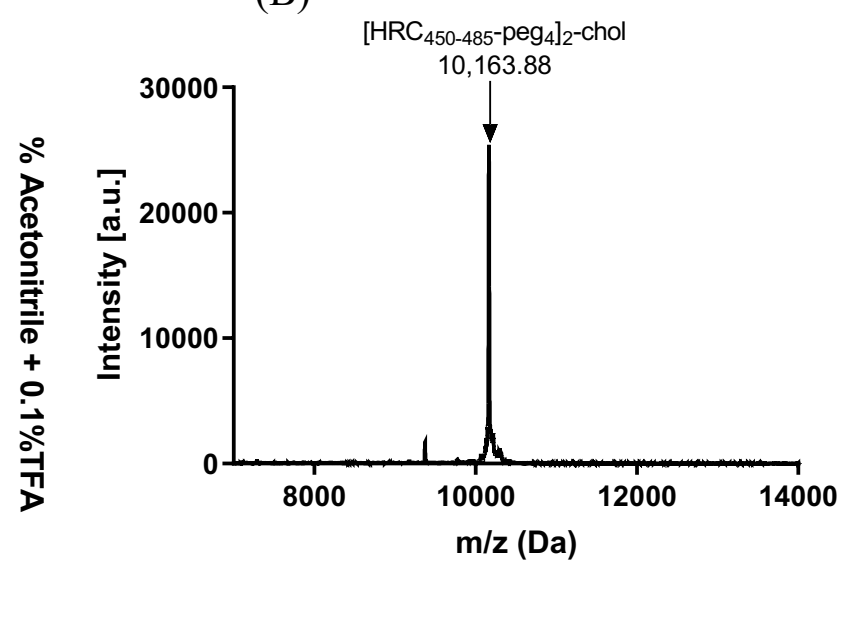

Fig. S8: HPLC and mass analysis of $\left[\mathrm{HRC}_{450-485}-\mathrm{PEG}_{4}\right]_{2}$-chol (A) RP HPLC chromatogram of the reaction mixture; (B) MALDI mass spectrum of $\left[\mathrm{HRC}_{450-485}-\mathrm{PEG}_{4}\right]_{2}$-chol [Calculated mass: 10,162.40; Observed mass: $10,163.88]$ 


\section{Synthesis of [FIP-PEG $\left.]_{2}\right]_{2}$-chol:}

[FIP-PEG 4$]_{2}$-chol was synthesized and purified following procedure (3). The HPLC trace of the reaction mixture (retention time of the product - $23.5 \mathrm{~min}$ ) and MALDI data of the product are shown below.

(A)

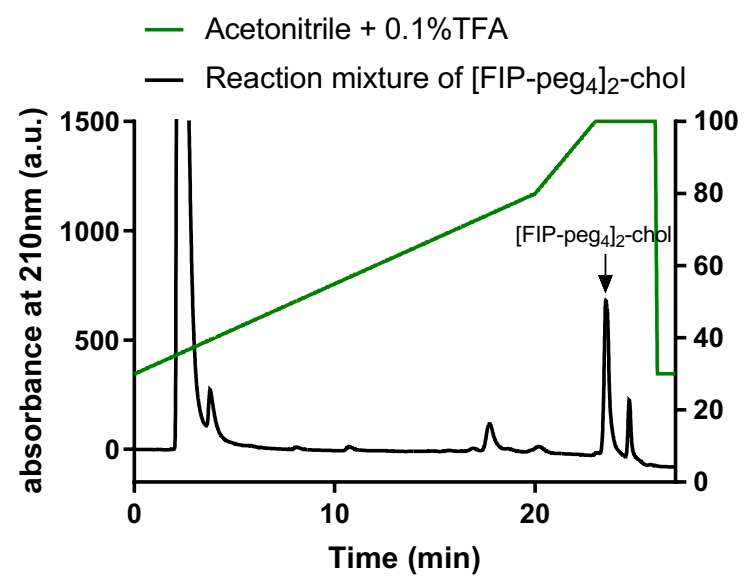

(B)

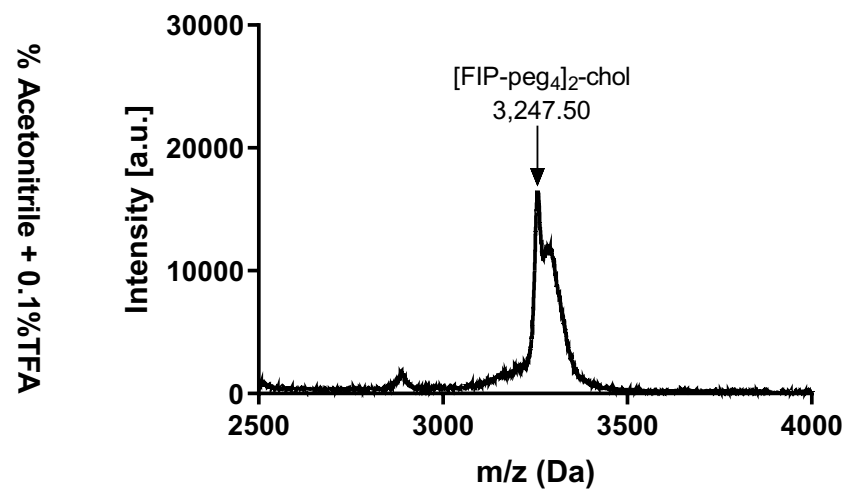

Fig. S9: HPLC and mass analysis of $[\text { FIP-PEG }]_{2}$-chol (A) RP HPLC chromatogram of the reaction mixture; (B) MALDI mass spectrum of [FIP-PEG $]_{2}$-chol [Calculated mass: 3,243.6; Observed mass: $3,247.50]$ 


\section{Synthesis of [peptide] $]_{2}-\mathbf{P E G}_{11}$ :}

General method to synthesize [peptide]2-PEG 11 conjugates (4):

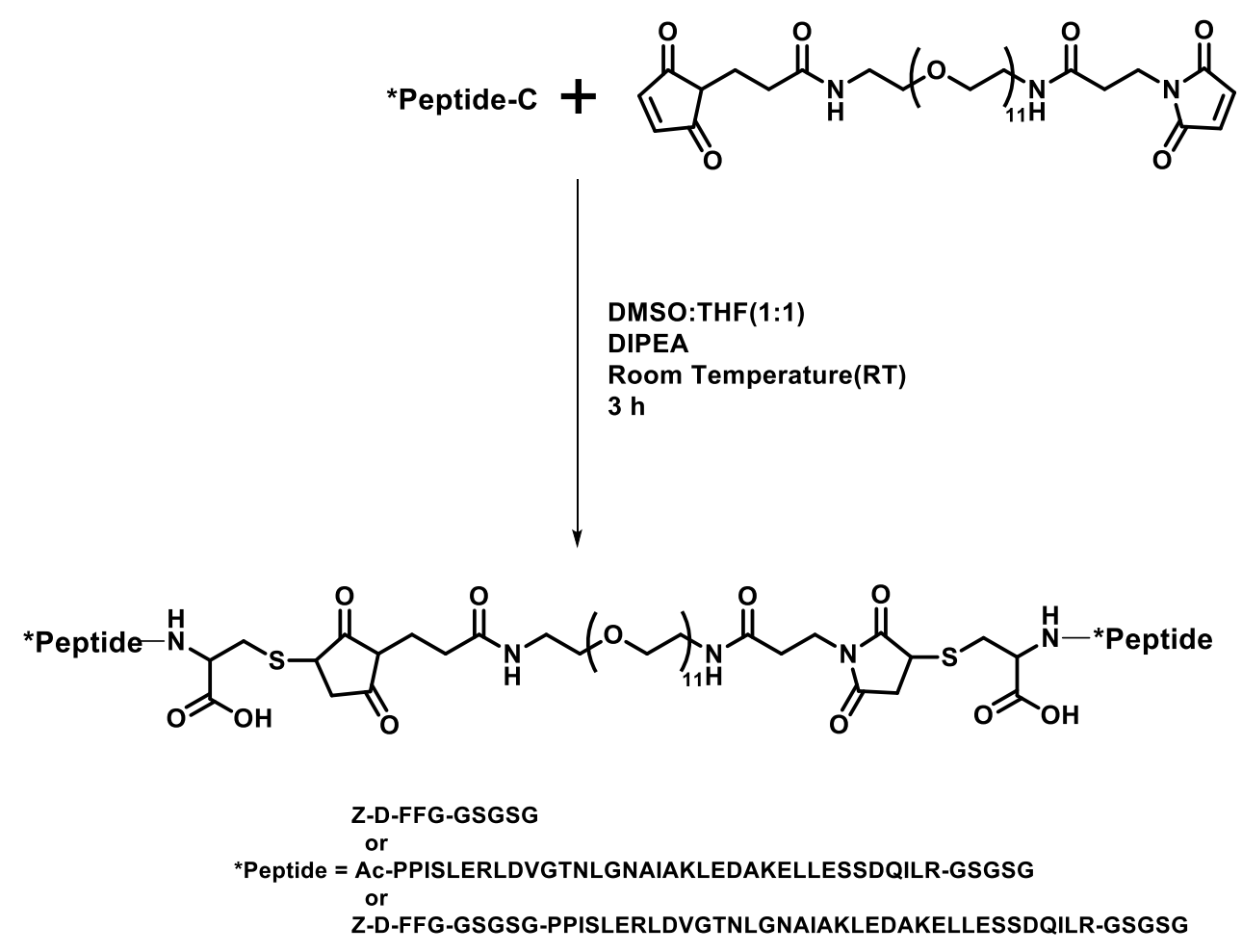

Scheme S4. Reaction scheme showing synthesis of [peptide] $]_{2}-\mathrm{PEG}_{11}$; *Peptide : C is cysteine in Peptide$\mathrm{C}$; Amino acid residues are represented in single letter code; Ac $=$ Acetylated $\mathrm{N}$-terminus; GSGSG $=$ linker containing five amino acids; D-FFG = D-amino acid was used for the first phenyl alanine residue; Z-D$\mathrm{FFG}=\mathrm{Z}$ is a carbobenzoxy residue attached to the $\mathrm{N}$-terminus of the $\mathrm{D}-\mathrm{FFG}$ sequence; $\mathrm{PEG}=$ polyethylene glycol.

$50 \mathrm{mg}$ of peptide, dissolved in $500 \mu \mathrm{L}$ of dimethylsulfoxide (DMSO), was added to bromoacetyl cholesterol (0.5 equivalent) dissolved in $500 \mu \mathrm{L}$ of tetrahydrofuran (THF), followed by the addition of $N, N$ diisopropylethylamine (DIPEA) (10 equivalent) to the solution. The solution was left stirring at room temperature for 3 hours, then purified by Phenomenex Jupiter C4 LC column $300 \AA(150 \times 21.2 \mathrm{~mm}$, particle size $5 \mu \mathrm{m}$ ) using as eluents: (A) $0.1 \%$ trifluoroacetic acid in water and (B) $0.1 \%$ trifluoroacetic acid in acetonitrile. The following linear gradient at a flow rate of $20 \mathrm{~mL} / \mathrm{min}$ was used: $15-45 \%$ (B) over 20 min, followed by $45-100 \%$ (B) in $3 \mathrm{~min}$, and then a wash step at $100 \%$ (B) for $3 \mathrm{~min}$. The desired peak was collected and lyophilized to give the product as white powder which was confirmed by MALDI. 


\section{Synthesis of [FIP-HRC $\left.{ }_{450-485}\right]_{2}-$ PEG $_{11}$ :}

[FIP-HRC $450-485]_{2}-\mathrm{PEG}_{11}$ was synthesized and purified following procedure (4). The HPLC trace of the reaction mixture (retention time of the product - $22.6 \mathrm{~min}$ ) and MALDI data of the product are shown below.
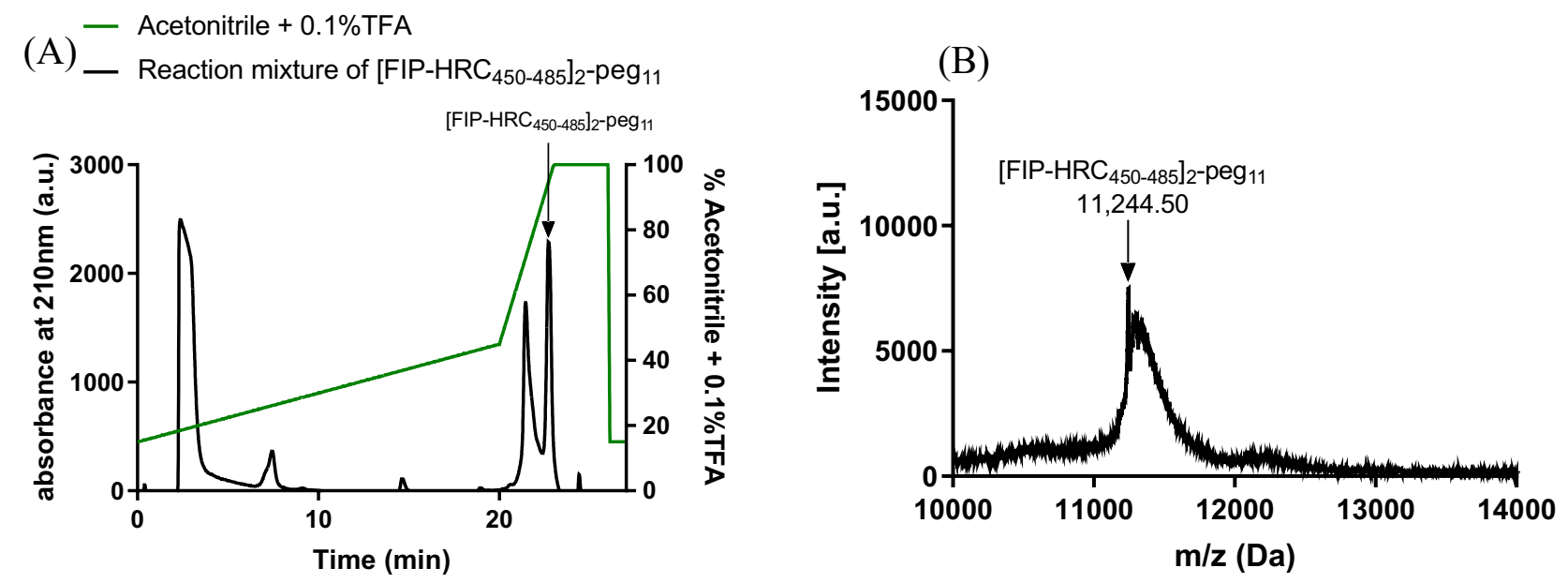

Fig. S10: HPLC and mass analysis of [FIP-HRC $450-485]_{2}-\mathrm{PEG}_{11}$ (A) RP HPLC chromatogram of the reaction mixture; (B) MALDI mass spectrum of [FIP-HRC $450-485]_{2}-$ PEG $_{11}$ [Calculated mass: 12,246.42; Observed mass: $12,244.50]$ 


\section{Synthesis of $\left[\mathrm{HRC}_{450-485}\right]_{2}-\mathrm{PEG}_{11}$ :}

$\left[\mathrm{HRC}_{450-485}\right]_{2}-\mathrm{PEG}_{11}$ was synthesized and purified following procedure (4). The HPLC trace of the reaction mixture (retention time of the product - $19.8 \mathrm{~min}$ ) and MALDI data of the product are shown below.
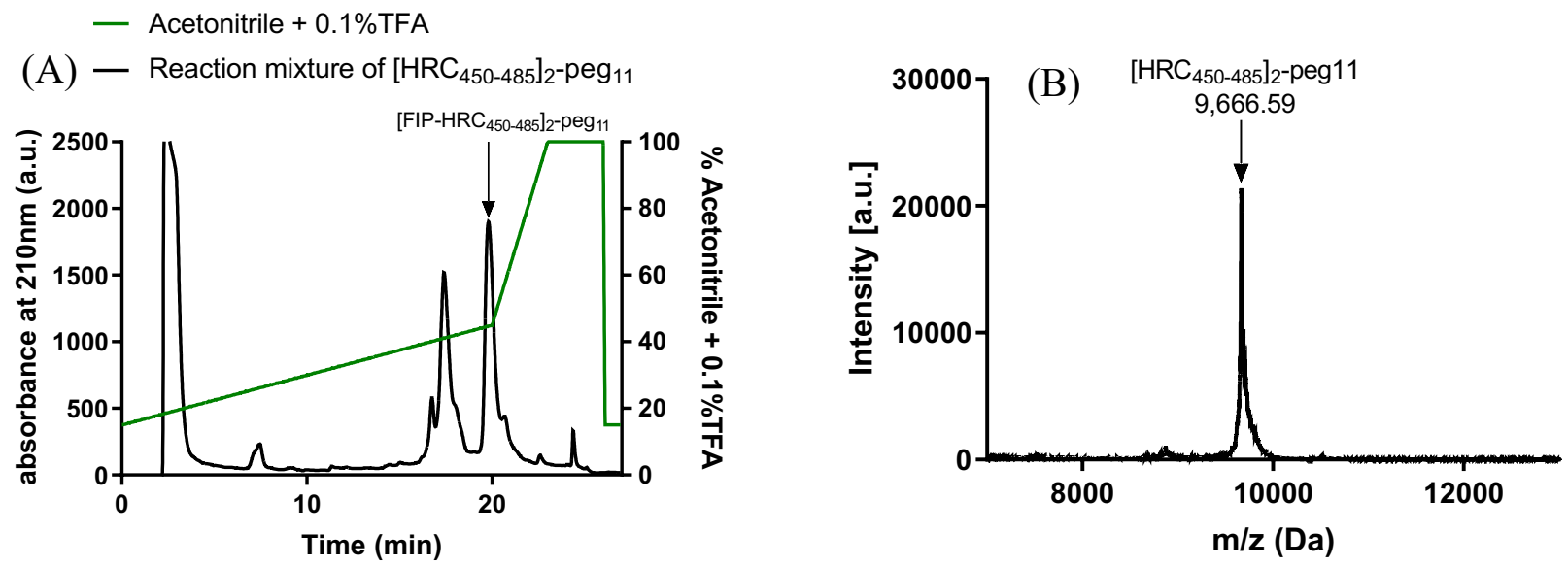

Fig. S11: HPLC and mass analysis of $\left[\mathrm{HRC}_{450-485}\right]_{2}-\mathrm{PEG}_{11}$ (A) RP HPLC chromatogram of the reaction mixture; (B) MALDI mass spectrum of [HRC $450-485]_{2}-\mathrm{PEG}_{11}$ [Calculated mass: 9,668.62; Observed mass: $9,666.59]$ 


\section{Synthesis of $[\mathrm{FIP}]_{2}-\mathrm{PEG}_{11}$ :}

$[\mathrm{FIP}]_{2}-\mathrm{PEG}_{11}$ was synthesized and purified following procedure (4). The HPLC trace of the reaction mixture (retention time of the product $-22.4 \mathrm{~min}$ ) and MALDI data of the product are shown below.

(A)

- Acetonitrile + 0.1\%TFA

- Reaction mixture of $[\mathrm{FIP}]_{2}-\mathrm{peg}_{11}$

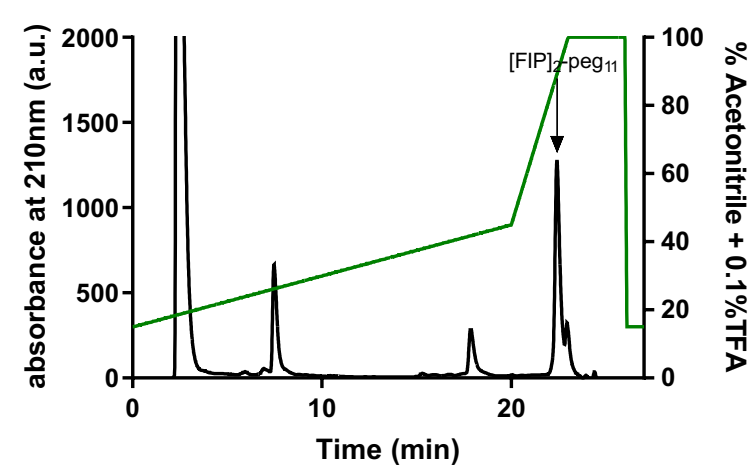

(B)

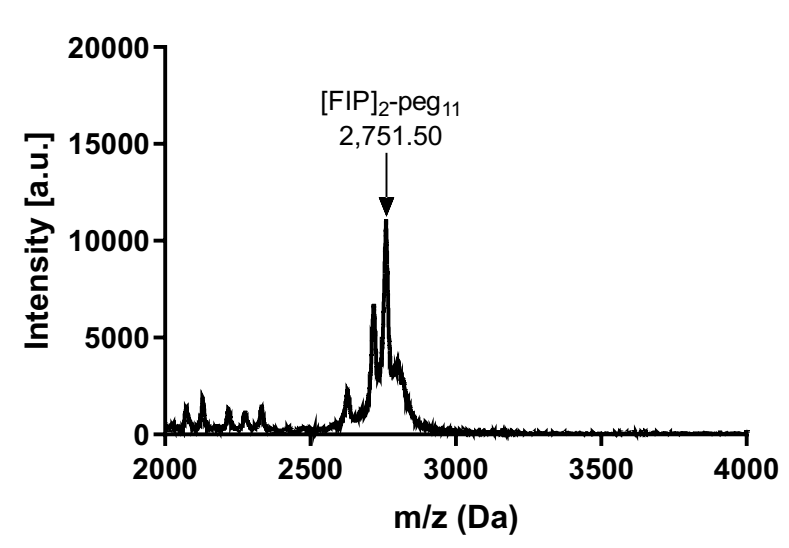

Fig. S12: HPLC and mass analysis of $[\mathrm{FIP}]_{2}-\mathrm{PEG}_{11}$ (A) RP HPLC chromatogram of the reaction mixture; (B) MALDI mass spectrum of [FIP] $]_{2}-\mathrm{PEG}_{11}$ [Calculated mass: 2,749.82; Observed mass: 2,751.50] 

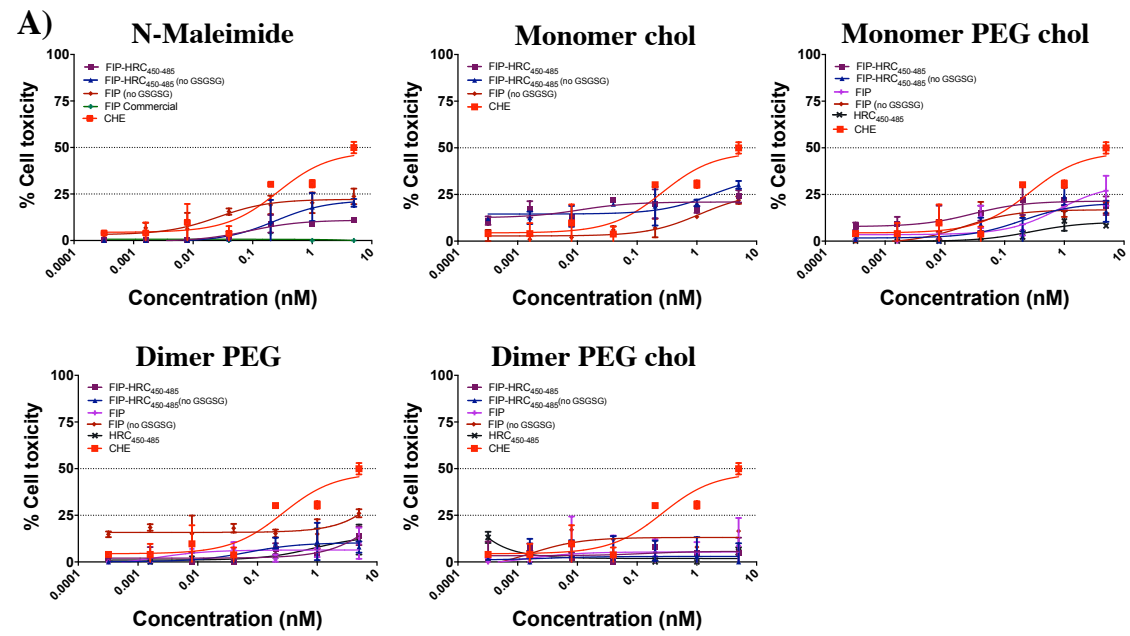

B)

\begin{tabular}{|c|c|c|}
\hline & Peptide & Therapeutic Index \\
\hline \multirow{4}{*}{ N-Maleimide } & FIP-HRC $C_{450-485}$ & $>5$ \\
\hline & FIP-HRC ${ }_{450-485}$ (no GSGSG) & $>7$ \\
\hline & FIP (no GSGSG) & $>5$ \\
\hline & FIP Commercial & $>0.5$ \\
\hline \multirow{3}{*}{ Monomer chol } & FIP-HRC ${ }_{450-485^{-}}$chol & $>30$ \\
\hline & FIP-HRC ${ }_{450-485^{-}}$chol (no GSGSG) & $>40$ \\
\hline & FIP-chol & $>0.5$ \\
\hline \multirow{5}{*}{ Monomer PEG chol } & $H R C_{450-485}-P G_{4}-$ chol & $>40$ \\
\hline & FIP-HRC $450-485-P E G_{4}-$ chol & $>32$ \\
\hline & FIP-HRC $450-485^{-}-P E G_{4}-$ chol (no GSGSG) & $>25$ \\
\hline & FIP-PEG ${ }_{4}-$ chol & $>1$ \\
\hline & FIP-PEG ${ }_{4}-$ chol (no GSGSG) & $>7$ \\
\hline \multirow{5}{*}{ Dimer PEG } & $H R C_{450-485}-P E G_{11}$ & $>1$ \\
\hline & FIP-HRC $C_{450-485}-P E G_{11}$ & $>17$ \\
\hline & $F I P-H R C_{450-485}-P E G_{11}$ (no GSGSG) & $>7$ \\
\hline & FIP-PEG 11 & $>0.5$ \\
\hline & FIP-PEG ${ }_{11}$ (no GSGSG) & $>7$ \\
\hline \multirow{5}{*}{ Dimer PEG chol } & {$\left[\mathrm{HRC}_{450-485}-\mathrm{PEG}_{4}\right]_{2}-\mathrm{chol}$} & $>20$ \\
\hline & {$\left[F I P-H R C_{450-485}-P_{\left.E G_{4}\right]_{2}-\text { chol }}\right.$} & $>250$ \\
\hline & {$\left[F I P-H R C_{450-485}-P E G_{4}\right]_{2}-$ chol (no GSGSG) } & $>55$ \\
\hline & {$\left[F I P-P E G_{4}\right]_{2}-$ chol } & $>15$ \\
\hline & {$\left[F I P-P E G_{4}\right]_{2}-c h o l(n o ~ G S G S G)$} & $>5$ \\
\hline
\end{tabular}

SFig 13. MeV peptides toxicity. MTT assay was used to determine the toxicity of the indicated peptides in HEK 293T cell cultures. The peptide was added to the media at several concentration up to $5 \mu \mathrm{M}$. Cell viability was determined after $24 \mathrm{~h}$. The peptides were not toxic at the concentrations tested (no peptide reached $50 \%$ toxicity, panel A). Based on the $\mathrm{IC}_{50}$ we calculated the minimal therapeutic index for each peptide (Panel B). 


\section{Dynamic light scattering (DLS):}

Lipid-peptide conjugates were dissolved in $100 \%$ DMSO to prepare $1 \mathrm{mM}$ stock solution. For dynamic light scattering (DLS), conjugate solutions with $5 \mu \mathrm{M}$ concentration were prepared from stock solution using water. All the samples were filtered through 0.2 micron filter paper to eliminate presence of any large particle. Measurements were performed in a Malvern Zetasizer Nano and consisted of 3 individual runs, each corresponding to an averaged autocorrelation curve obtained from 15 repeated sample scans.

- Particle size of $\left[\mathrm{HRC}_{450-485} \text {-peg4 }\right]_{2}$-chol $140 \mathrm{~nm}$

- Particle size of $\left[\mathrm{FIP}-\mathrm{HRC} \mathrm{C}_{450-485} \text {-peg4 }\right]_{2}$-chol $\sim 60 \mathrm{~nm}$

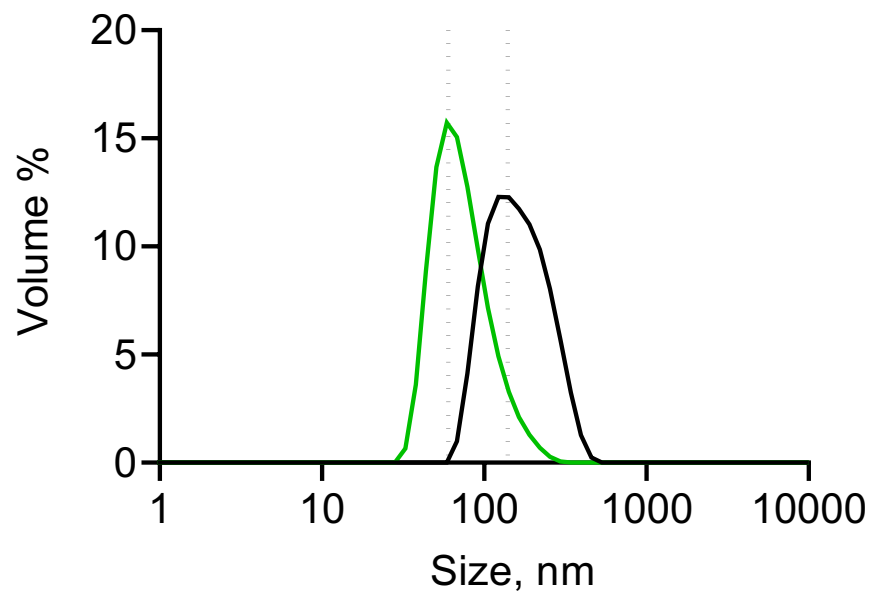

SFig. 14: Volume distribution data of [HRC450-485-PEG $]_{2}$-chol and [FIP-HRC $\left.450-485-\mathrm{PEG}_{4}\right]_{2}$-chol in DLS; Attenuator (gain) (Count Rate) for [FIP-HRC $\left.450-485-\mathrm{PEG}_{4}\right]_{2}$-chol: 9, (159.6); Attenuator (gain) (Count Rate) for $\left[\mathrm{HRC}_{450}-485-\mathrm{PEG}_{4}\right]_{2}$-chol: 8, (284.4) 
STable 2. Inhibitory activity of FIP, HRC, and FIP-HRC peptides in fusion assays (extended version). The beta-galactosidase complementation-based fusion assay was performed as described previously. Briefly, HEK 293T cells transiently transfected with either nectin-4 or CD150 and the omega reporter subunit ("target cells") were incubated for the indicated period with cells co-expressing viral glycoproteins ( $\mathrm{H}$ and F) and the alpha reporter subunit ("effector cells"), in the presence or absence of fusion inhibitor peptides. In the absence of peptides the fusion between the target and effector cells permits reconstitution of the beta-galactosidase activity, which is quantified using the luminescence based kit Galacto-Star ${ }^{\mathrm{TM}} \beta$ Galactosidase Reporter Gene (ThermoFisher, US). In the presence of peptides fusion is reduced, with resultant reduction in beta-gal activity. Data are means $( \pm \mathrm{SE})$ from at least three experiments.

\begin{tabular}{|c|c|c|c|c|c|}
\hline & \multirow[t]{2}{*}{ Peptide } & \multicolumn{2}{|c|}{ Nectin 4} & \multicolumn{2}{|c|}{ CD150 } \\
\hline & & $I \mathbf{C}_{50}$ & $\mathbf{I C}_{90}$ & $\mathrm{IC}_{50}$ & $I C_{90}$ \\
\hline \multirow{11}{*}{ Monomer } & $\mathrm{HRC}_{450-485}$ & $>10000$ & $>10000$ & & \\
\hline & $\mathrm{HRC}_{450-\mathrm{CR}_{-485}}$ & $>10000$ & $>10000$ & & \\
\hline & $\mathrm{HRC}_{451-486}$ & $>10000$ & $>10000$ & & \\
\hline & $\mathrm{HRC}_{451-\mathrm{CS}-486}$ & $>10000$ & $>10000$ & & \\
\hline & $\mathrm{HRC}_{443-478}$ & $>10000$ & $>10000$ & & \\
\hline & $\mathrm{HRC}_{443-\mathrm{CE}-478}$ & $>10000$ & $>10000$ & & \\
\hline & FIP-HRC $450-485$ & $4250 \pm 815$ & $>10000$ & & \\
\hline & FIP-HRC $450-485$ (no GSGSG) & $2768 \pm 1645$ & $6371 \pm 4185$ & & \\
\hline & FIP & $9717 \pm 2730$ & $>10000$ & & \\
\hline & FIP Commercial & $>10000$ & $>10000$ & & \\
\hline & $3 \mathrm{~g}$ & $>10000$ & $>10000$ & & \\
\hline \multirow{3}{*}{ N-Maleimide } & FIP-HRC $450-485$ & $>1000$ & $>1000$ & $>1000$ & $>1000$ \\
\hline & FIP-HRC $450-485$ (no GSGSG) & $>700$ & $>1000$ & $>1000$ & $>1000$ \\
\hline & FIP (no GsGsG) & $>1000$ & $>1000$ & $>1000$ & $>1000$ \\
\hline \multirow{10}{*}{ Monomer Chol } & $\mathrm{HRC}_{450-485}$-chol & $103 \pm 11$ & - & & \\
\hline & $\mathrm{HRC}_{451-486}$-chol & $180 \pm 15$ & $1450 \pm 50$ & & \\
\hline & $\mathrm{HRC}_{443-478-\mathrm{chol}}$ & $3300 \pm 380$ & $>10000$ & & \\
\hline & FIP-HRC ${ }_{450-485}$-chol & $155 \pm 20$ & $630 \pm 250$ & $185 \pm 46$ & $845 \pm 27$ \\
\hline & FIP-HRC ${ }_{450-485-{ }^{-c h o l ~(n o ~ G S G S G) ~}}$ & $114 \pm 40$ & $425 \pm 70$ & $71 \pm 65$ & $389 \pm 22$ \\
\hline & FIP-chol & $>10000$ & $>10000$ & & \\
\hline & FIP-chol (no GSGSG) & $>1000$ & $>1000$ & $>1000$ & $>1000$ \\
\hline & Chol-HRC $_{450-C R-485}$ & $4560 \pm 950$ & $>10000$ & & \\
\hline & $\mathrm{Chol}-\mathrm{HRC}_{451-\mathrm{CS}-486}$ & $2745 \pm 30$ & $8165 \pm 45$ & & \\
\hline & Chol-HRC $_{443-C E-478}$ & $7635 \pm 450$ & $>10000$ & & \\
\hline \multirow{10}{*}{ Monomer PEG Chol } & $\mathrm{HRC}_{450-485}-\mathrm{PEG}_{4}-\mathrm{Chol}$ & $125 \pm 11$ & $860 \pm 80$ & & \\
\hline & $\mathrm{HRC}_{451-486}-\mathrm{PEG}_{4}$-chol & $140 \pm 57$ & $791 \pm 293$ & & \\
\hline & $\mathrm{HRC}_{443-478}-\mathrm{PEG}_{4}-\mathrm{Chol}$ & $145 \pm 50$ & $1625 \pm 155$ & & \\
\hline & FIP-HRC ${ }_{450-485}-\mathrm{PEG}_{4}-\mathrm{chol}$ & $155 \pm 17$ & $550 \pm 145$ & $124 \pm 12$ & $618 \pm 178$ \\
\hline & FIP-HRC ${ }_{450-485}-$ PEG $_{4}$-chol (no GSGSG) & $200 \pm 60$ & $761 \pm 214$ & $79 \pm 33$ & $278 \pm 27$ \\
\hline & FIP-PEG ${ }_{4}$-chol & $4005 \pm 1083$ & $7615 \pm 13$ & & \\
\hline & FIP-PEG ${ }_{4}$-chol (no GSGSG) & $>700$ & $>1000$ & $>400$ & $>900$ \\
\hline & $\mathrm{Chol}_{-\mathrm{PEG}_{4}-\mathrm{HRC}_{450}{ }_{485}}$ & $>5000$ & $>9000$ & & \\
\hline & Chol-PEG $_{4}-\mathrm{HRC}_{451-486}$ & $>3000$ & $>6000$ & & \\
\hline & Chol-PEG $_{4}-\mathrm{HRC}_{443-478}$ & $>10000$ & $>10000$ & & \\
\hline \multirow{10}{*}{ Dimer PEG } & {$\left[\mathrm{HRC}_{450-485}\right]_{2}-\mathrm{PEG}_{11}$} & $>4000$ & $>10000$ & & \\
\hline & {$\left[\mathrm{HRC}_{451-486}\right]_{2}-\mathrm{PEG}_{11}$} & $>10000$ & $>10000$ & & \\
\hline & {$\left[\mathrm{HRC}_{443-478}\right]_{2}-\mathrm{PEG}_{11}$} & $>10000$ & $>6000$ & & \\
\hline & {$\left[\mathrm{FIP}-\mathrm{HRC} \mathrm{A50-485}_{2}\right]_{2}-\mathrm{PEG}_{11}$} & $287 \pm 31$ & $2292 \pm 147$ & $283 \pm 165$ & $945 \pm 95$ \\
\hline & {$\left[\mathrm{FIP}-\mathrm{HRC}_{450-485}\right]_{2}-\mathrm{PEG}_{11 \text { (no GSGSG) }}$} & $>700$ & $>1000$ & $517 \pm 105$ & $>1000$ \\
\hline & {$[\mathrm{FIP}]_{2}-\mathrm{PEG}_{11}$} & $>10000$ & $>10000$ & $>1000$ & $>1000$ \\
\hline & {$[\mathrm{FIP}]_{2}-\mathrm{PEG}_{11 \text { (no GSGSG) }}$} & $>700$ & $>1000$ & $>600$ & $>1000$ \\
\hline & $\mathrm{PEG}_{11-}\left[\mathrm{HRC}_{450-485}\right]_{2}$ & $>10000$ & $>10000$ & & \\
\hline & $\mathrm{PEG}_{11-\left[\mathrm{HRC}_{451-486}\right]_{2}}$ & $>10000$ & $>10000$ & & \\
\hline & $\mathrm{PEG}_{11-\left[\mathrm{HRC}_{443-478}\right]_{2}}$ & $>8000$ & $>10000$ & & \\
\hline \multirow{10}{*}{ Dimer PEG chol } & {$\left[\mathrm{HRC}_{450-485}-\mathrm{PEG}_{4}\right]_{2}$-chol } & $250 \pm 10$ & $400 \pm 38$ & $100 \pm 65$ & $700 \pm 30$ \\
\hline & {$\left[\mathrm{HRC}_{451-486}-\mathrm{PEG}_{4}\right]_{2}-\mathrm{chol}$} & $158 \pm 72$ & $1053 \pm 534$ & & \\
\hline & {$\left[\mathrm{HRC}_{443-478}-\mathrm{PEG}_{4}\right]_{2}-\mathrm{chol}$} & $285 \pm 157$ & $4397 \pm 1783$ & & \\
\hline & {$\left[\mathrm{FIP}-\mathrm{HRC}_{450-485}-\mathrm{PEG}_{4}\right]_{2}$-chol } & $20 \pm 10$ & $100 \pm 40$ & $26 \pm 12$ & $125 \pm 10$ \\
\hline & [FIP-HRC $\left.450-485-\mathrm{PEG}_{4}\right]_{2}$-chol (no GSGSG) & $90 \pm 60$ & & $61 \pm 12$ & $142 \pm 37$ \\
\hline & {$\left[\mathrm{FIP}-\mathrm{PEG}_{4}\right]_{2}$-chol } & $300 \pm 50$ & $1850 \pm 20$ & $510 \pm 360$ & $930 \pm 60$ \\
\hline & {$\left[\mathrm{FIP}-\mathrm{PEG}_{4}\right]_{2}$-chol (no GSGSG) } & $>1000$ & $>1000$ & $>700$ & $>1000$ \\
\hline & Chol-[PEG $\left.4-\mathrm{HRC}_{450-485}\right]_{2}$ & $>1000$ & $>6000$ & & \\
\hline & Chol-[PEG $4-\mathrm{HRC}_{451-486]_{2}}$ & $414 \pm 100$ & $>4000$ & & \\
\hline & Chol-[PEG $\left.4-\mathrm{HRC}_{443-478}\right]_{2}$ & $>6000$ & $>10000$ & & \\
\hline
\end{tabular}


STable 3. Stabilization properties of FIP, HRC, and FIP-HRC peptides (extended version). The thermostability assay was performed as described previously. Briefly, HEK 293T cells were transfected with viral glycoprotein constructs and left overnight at $37^{\circ} \mathrm{C}$. After a brief incubation on ice, the cells were treated with several concentrations of the peptides $(1,10,100$ and $1000 \mathrm{nM})$ and then subjected to incubation at $55^{\circ} \mathrm{C}$ for $10^{\prime}$. The cells were then incubated with mouse monoclonal antibodies that recognize the prefusion conformation of MeV F (1:1000) for $1 \mathrm{~h}$ on ice. Cells were washed with PBS and then incubated for $1 \mathrm{~h}$ on ice with anti-mouse secondary antibody (1:500, Alexa Fluor 488 goat). Percentages of prefusion signal were determined using Cell Profile software. Data (unless for ${ }^{\circ}=5$ replicates and $\S=6$ replicates) are from three independent experiments.

\begin{tabular}{|c|c|c|c|}
\hline & Peptide & $\mathbf{S C}_{50}$ & $\mathbf{S C}_{90}$ \\
\hline \multirow{5}{*}{ Monomer } & $\mathrm{HRC}_{450-485}$ & $>700$ & $>1000$ \\
\hline & FIP-HRC $450-485$ & $>1000$ & $>1000$ \\
\hline & FIP & $720 \pm 6$ & $900 \pm 35$ \\
\hline & FIP Commercial & $>1000$ & $>1000$ \\
\hline & $3 g$ & $>1000$ & $>1000$ \\
\hline \multirow{3}{*}{ N-Maleimide } & FIP-HRC $_{450-485}$ & $>1000$ & $>1000$ \\
\hline & FIP-HRC $450-485$ (no GSGSG) & $>1000$ & $>1000$ \\
\hline & FIP (no GSGSG) & $>1000$ & $>1000$ \\
\hline \multirow{5}{*}{ Monomer Chol } & FIP-HRC $_{450-485-\text { chol }}$ & $274 \pm 179$ & $>540$ \\
\hline & FIP-HRC $450-485-$ chol (no GSGSG) $_{1}$ & $101 \pm 74$ & $460 \pm 218$ \\
\hline & FIP-chol & $>1000$ & $>1000$ \\
\hline & FIP-chol (no GSGSG) & $>1000$ & $>1000$ \\
\hline & $\mathrm{HRC}_{450-485}-\mathrm{PEG}_{4}-\mathrm{chol}$ & $>1000$ & $>1000$ \\
\hline \multirow{4}{*}{$\begin{array}{c}\text { Monomer PEG } \\
\text { Chol }\end{array}$} & FIP-HRC $450-485-P^{-} G_{4-c h o l}$ & $273 \pm 182$ & $610 \pm 34$ \\
\hline & FIP-HRC $450-485-$ PEG $_{4}$-chol (no GSGSG) & $256 \pm 110$ & $652 \pm 158$ \\
\hline & FIP-PEG 4 -chol & $>1000$ & $>1000$ \\
\hline & FIP-PEG $_{4}$-chol (no GSGSG) & $>1000$ & $>1000$ \\
\hline \multirow{5}{*}{ Dimer PEG } & {$\left[\mathrm{HRC}_{450-485}\right]_{2}-\mathrm{PEG}_{11}$} & $>1000$ & $>1000$ \\
\hline & {$\left[\mathrm{FIP}-\mathrm{HRC}{ }_{450-485]_{2}-\mathrm{PEG}_{11} \S}\right.$} & $305 \pm 93$ & $>1000$ \\
\hline & [FIP-HRC $450-485]_{2}-\mathrm{PEG}_{11}$ (no GSGSG) & $>630$ & $>1000$ \\
\hline & {$[\mathrm{FIP}]_{2}-\mathrm{PEG}_{11} \circ$} & $262 \pm 247$ & $>730$ \\
\hline & {$[F I P]_{2}-P E G_{11}$ (no GSGSG) } & $>1000$ & $>1000$ \\
\hline \multirow{5}{*}{ Dimer PEG Chol } & {$\left[\mathrm{HRC}_{450-485}-\mathrm{PEG}_{4}\right]_{2}$-chol } & $>1000$ & $>1000$ \\
\hline & {$\left[\mathrm{FIP}-\mathrm{HRC}{ }_{450-485}-\mathrm{PEG}_{4}\right]_{2}-\mathrm{chol}_{\S}$} & $38 \pm 12$ & $80 \pm 20$ \\
\hline & [FIP-HRC $\left.450-485-\mathrm{PEG}_{4}\right]_{2}$-chol (no GSGSG) & $23 \pm 13$ & $100 \pm 46$ \\
\hline & {$[\text { FIP-PEG } 4]_{2}-\mathrm{Chol}_{\S}$} & $233 \pm 66$ & $320 \pm 150$ \\
\hline & [FIP-PEG 4$]_{2}$-chol (no GSGSG) & $>1000$ & $>1000$ \\
\hline
\end{tabular}




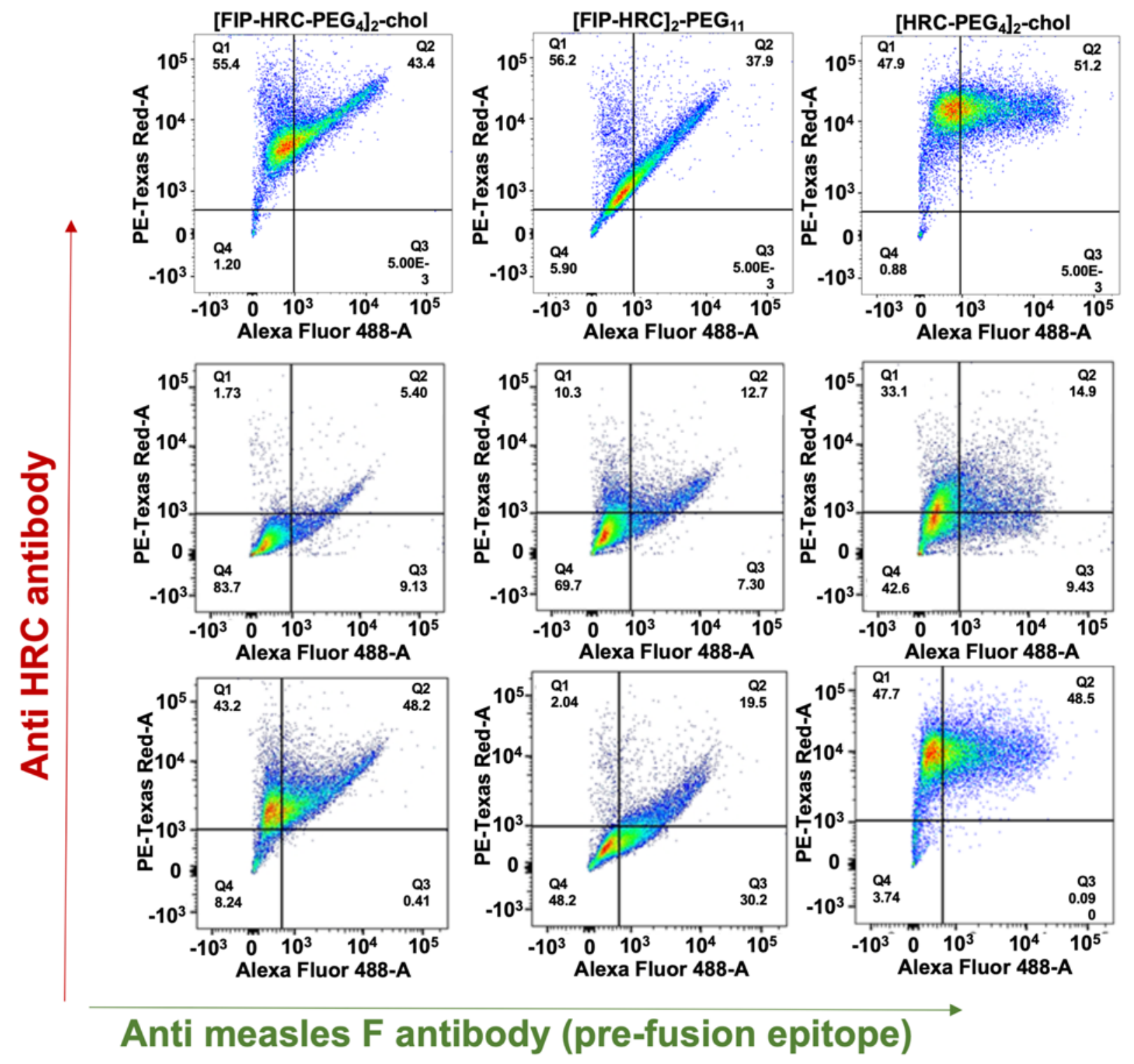

SFig. 15. The FIP-HRC peptide targets MeV F expressing cells. Localization of [FIP-HRC-PEG $]_{2}$-chol peptide in HEK 293 T cells. HEK 293T cells expressing MV F were incubated with peptide (1000nM) for 60 min at $37^{\circ} \mathrm{C}$. F protein and HRC-FIP peptide were stained with Alexa Fluor 488 (green, x-axis) and Alexa Fluor 594 (red, y-axis), respectively. Representative of three separate experiments. For the FIP-HRC with cholesterol, the HRC signal is directly proportional to the F signal suggesting that the FIP-HRC is targeted to the F-expressing cells. FIP alone (without cholesterol) localizes the HRC to F expressing cells but with lower HRC signal. When lipid is present but FIP is missing the HRC is not as specifically localized to the F-expressing cells. Data from three separate experiments. 

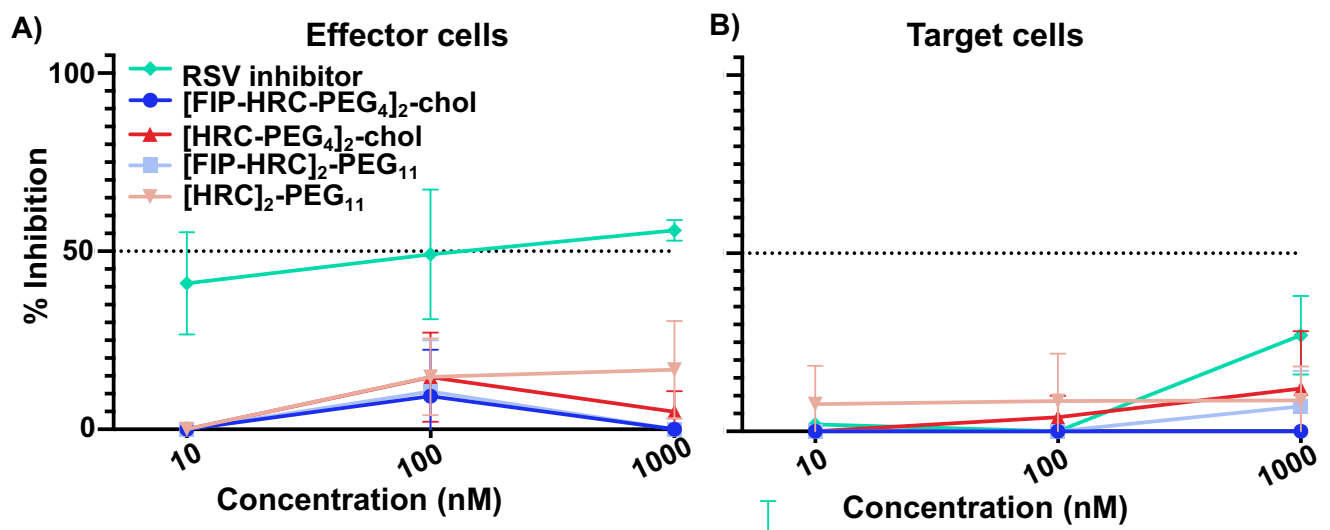

SFig.16 Specificity of MeV lipopeptides. (A) HEK 293T cells expressing viral glycoprotein (RSV F) and the alpha reporter subunit of beta-gal ("effector" cells) were incubated for $1 \mathrm{~h}$ at $37^{\circ} \mathrm{C}$ with [FIP-HRC$\left.\mathrm{PEG}_{4}\right]_{2}$-chol, [HRC-PEG $]_{2}$-chol, [FIP-HRC $]_{2}-\mathrm{PEG}_{11},[\mathrm{HRC}]_{2}-\mathrm{PEG}_{11}$ and RSV inhibitor at the indicated concentrations (x-axis). After $1 \mathrm{~h}$ the cells were washed with DPBS to remove unbound peptide and the cells were incubated with cells expressing the omega reporter subunit of beta-gal. (B) The same process was repeated with $293 \mathrm{~T}$ cells expressing the omega reporter subunit of beta-gal ("target" cells) and after $1 \mathrm{~h}$ the cells were washed with DPBS and incubated with the "effector" cells. A quantitative cell-cell fusion assay based on $\beta$-galactosidase ( $\beta$-gal) complementation was performed to measure fusion after $6 \mathrm{~h}$. Incubation of [FIP-HRC- $\left.\mathrm{PEG}_{4}\right]_{2}$-chol (blue line) with effector or target cells reduced fusion, although it was removed prior to the assay. MeV lipopeptides did not block RSV fusion, while the RSV-specific compound inhibited RSV fusion after pre-incubation with effector cells, as expected. 


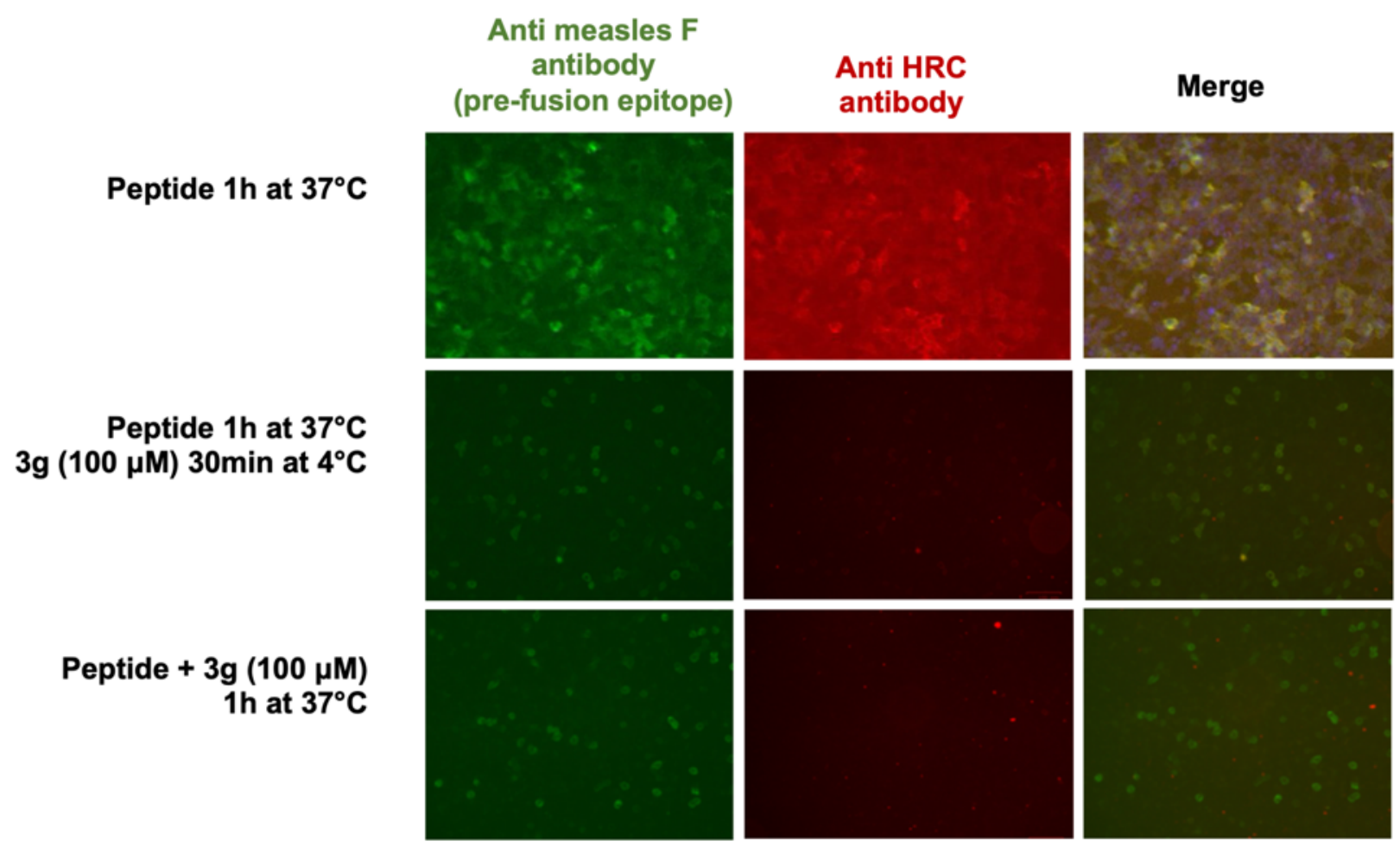

SFig17. The localization of [FIP-HRC] $]_{2}-$ PEG $_{11}$ peptide in HEK 293T cells. HEK 293T cell cultures expressing MeV F were incubated with the peptide $(1000 \mathrm{nM})$ at $37^{\circ} \mathrm{C}$ for $60 \mathrm{~min}$. F protein and HRC-FIP peptide were stained with Alexa Fluor 488 (green) and Alexa Fluor 594 (red), respectively. Yellow staining (merge image) indicates F protein and FIP-HRC peptide colocalization. Co-incubation in the presence of $100 \mu \mathrm{M}$ of $3 \mathrm{~g}$ prevented $\mathrm{F}$ specific localization. 
A) Reversibly bound RBC
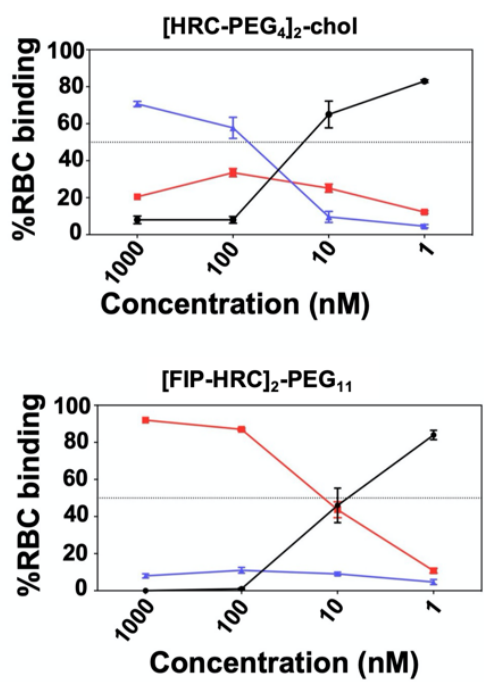

Fused RBC [FIP-HRC-PEG $]_{2}$-chol
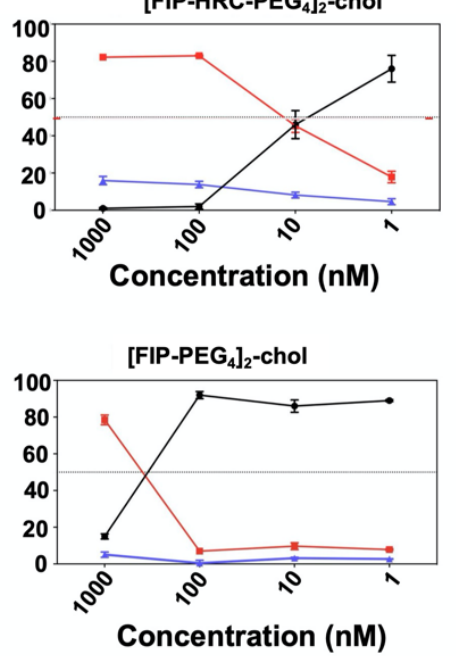

B) $\left[H R C-P E G_{4}\right]_{2}-$ chol $\left[F I P-H R C-P E G_{4}\right]_{2}-$ chol $\left[F I P-P E G_{4}\right]_{2}-$ chol
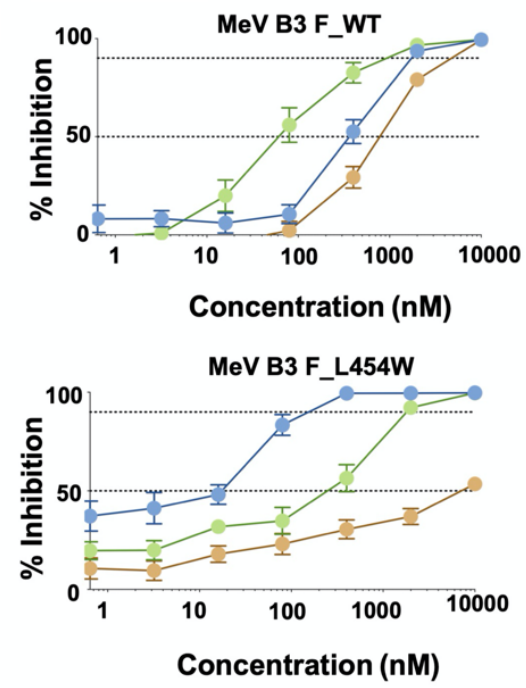

SFig. 18. [FIP-HRC-PEG $]_{2}$-chol prevents $F$ activation by interaction with HRC domain (A) [FIPHRC-PEG $\left.]_{4}\right]_{2}$-chol peptide prevents F activation. HEK 293T cells co-expressing H-HN T193A (a chimeric binding protein containing the MeV stalk and the HPIV3 head that binds sialic acid receptors and triggers $\mathrm{MeV} \mathrm{F}$ ) and MeV F (S262R, an easily activated F) were allowed to bind to sialic acid receptorbearing red blood cells (RBCs) at $4^{\circ} \mathrm{C}$. Upon transfer to $37^{\circ} \mathrm{C}$, media containing the indicated compound or peptide (x-axis) were added for 60', and then $10 \mathrm{mM}$ zanamivir was added to release the RBCs that were reversibly bound (i.e., bound only by $\mathrm{H}-\mathrm{HN}$ and not by $\mathrm{F}$ insertion). RBCs that are reversibly bound by $\mathrm{HN}$-receptor interaction (red), irreversibly bound by $\mathrm{F}$ insertion (blue), or fused (black) were quantified. The ordinate values are means $( \pm \mathrm{SE})$ of results from triplicate experiments. [HRC-PEG 4$]_{2}$-chol blocks fusion after $\mathrm{F}$ insertion into the target cell (irreversibly bound, blue). [FIP-HRC-PEG $]_{2}$-chol blocks at the pre-fusion state (reversibly bound, orange). Zanamivir released all the $\mathrm{RBC}$ when added at the beginning of the $37^{\circ} \mathrm{C}$ incubation. (B) [FIP-HRC-PEG $\left.]_{2}\right]_{2}$-chol peptide interacts with HRC domain. HEK 293T cells transiently transfected with nectin-4 and the omega reporter subunit of beta-gal ("target cells") were incubated with cells co-expressing viral glycoproteins $\mathrm{H}$ and $\mathrm{F}$ wild type or MeV F bearing L454W mutation and the alpha reporter subunit of beta-gal ("effector cells") in the presence or in absence of the indicated peptides. In the absence of peptides, fusion between the target and effector cells permits reconstitution of beta-galactosidase activity, quantified using the luminescence-based kit, Galacto-Star ${ }^{\mathrm{TM}}$ $\beta$-Galactosidase Reporter Gene (ThermoFisher, US). The [FIP-HRC-PEG $]_{2}$-chol peptide exhibits the most potent inhibitory activity against membrane fusion mediated by $\mathrm{MeV} \mathrm{F}_{-}$wild type. The [HRC-PEG $]_{2}-\mathrm{chol}$ peptide has successfully inhibited similar MeV variants (F_L454W). The data presented is the mean of three independent experiments $( \pm \mathrm{SE})$. 